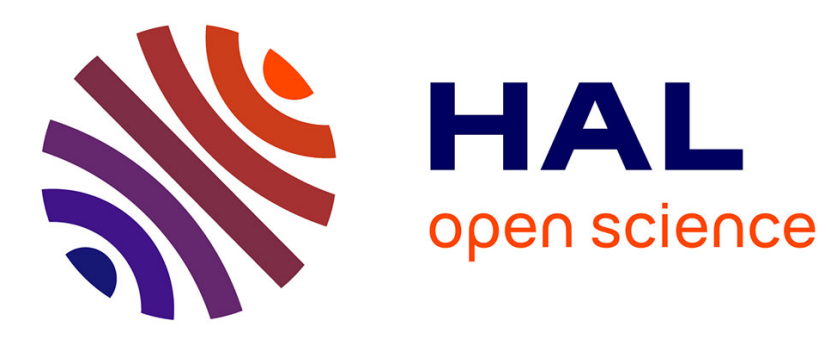

\title{
Collision Cross Sections of Phosphoric Acid Cluster Anions in Helium Measured by Drift Tube Ion Mobility Mass Spectrometry
}

Valentina Calabrese, Hélène Lavanant, Frédéric Rosu, Valérie Gabelica, Carlos Afonso

\section{- To cite this version:}

Valentina Calabrese, Hélène Lavanant, Frédéric Rosu, Valérie Gabelica, Carlos Afonso. Collision Cross Sections of Phosphoric Acid Cluster Anions in Helium Measured by Drift Tube Ion Mobility Mass Spectrometry. Journal of The American Society for Mass Spectrometry, 2020, 31 (4), pp.969-981. 10.1021/jasms.0c00034 . hal-02541705

HAL Id: hal-02541705

https://hal-normandie-univ.archives-ouvertes.fr/hal-02541705

Submitted on 26 Apr 2021

HAL is a multi-disciplinary open access archive for the deposit and dissemination of scientific research documents, whether they are published or not. The documents may come from teaching and research institutions in France or abroad, or from public or private research centers.
L'archive ouverte pluridisciplinaire HAL, est destinée au dépôt et à la diffusion de documents scientifiques de niveau recherche, publiés ou non, émanant des établissements d'enseignement et de recherche français ou étrangers, des laboratoires publics ou privés. 
COLLISION CROSS SECTIONS OF PHOSPHORIC ACID CLUSTER ANIONS IN HELIUM MEASURED BY DRIFT TUBE ION MOBILITY MASS SPECTROMETRY

Valentina Calabrese ${ }^{1}$, Hélène Lavanant ${ }^{1 *}$, Frédéric Rosu루, Valérie Gabelica ${ }^{3}$, Carlos Afonso ${ }^{1}$

${ }^{1}$ Normandie Univ, UNIROUEN, INSA Rouen, CNRS, COBRA, 76000 Rouen, France

${ }^{2}$ CNRS, University of Bordeaux and INSERM, Institut Européen de Chimie et Biologie (IECB, UMS3033, US001), 2 rue Robert Escarpit, 33600 Pessac, France

3 University of Bordeaux, INSERM and CNRS, Laboratoire Acides Nucléiques: Régulations Naturelle et Artificielle (ARNA, U1212, UMR5320), site IECB, 2 rue Robert Escarpit, 33600 Pessac, France

* Address reprint requests to

Hélène Lavanant

Université de Rouen

IRCOF, 1 Rue Tesnière, 76821 Mont Saint Aignan Cedex, France.

Tel : +33235522932

helene.lavanant@univ-rouen.fr

Key Words: Ion mobility, mass spectrometry, phosphoric acid, clusters, hydrogen bonds, instrument performance evaluation, collision cross section.

\section{Abstract}

In the last years, ion mobility mass spectrometry (IMS-MS) has improved structural analysis and compound identification by giving access to the collision cross section (CCS). An increasingly wide and accurate database of CCS values is now available but often without assessment of the influence of different instrumental settings on CCS values. Here, we present $75 \mathrm{CCS}$ values in helium $\left({ }^{\mathrm{DT}} \mathrm{CCS}_{\mathrm{He}}\right)$ for phosphoric acid cluster anions $\left[\left(\mathrm{H}_{3} \mathrm{PO}_{4}\right)_{n}-\mathrm{zH}\right]^{z^{-}}$with charge state $(z)$ up to $4-$. The CCS values, noted ${ }^{\mathrm{DT}} \mathrm{CCS}_{\mathrm{He}}$, were obtained with a commercial drift tube ion mobility mass spectrometer, in helium, by applying a classic multi-field approach. Phosphoric acid clusters are fragile structures that allow to evaluate the effect of different experimental conditions on the retention of weak bonds and their effect on CCS values. We probed harsh and soft voltage gradients in the electrospray (ESI) source before the IMS and two different voltage gradients in the post-IMS region. The variations in the ion mobility and mass spectra consisted in a change in the distribution of the cluster anions aggregation numbers $(n)$ and charge states $(z)$, with a higher amount of multiply charged species for the soft pre-IMS voltage gradient and a lower proportion of cluster dissociation for soft post-IMS conditions. However, the CCS values did not change with experimental conditions for a given cluster, as long as it stays intact from the IMS to the mass analyser. The ${ }^{\mathrm{DT}} \mathrm{CCS}_{\mathrm{He}}$ were found in good agreement among 3 to 10 replicated values, with a relative standard deviation between $0.1-1.7 \%$. 


\section{Introduction}

Ion mobility spectrometry (IMS) separates ionized species in the gas phase by exploiting the balance between the force exerted by a weak electric field $(E)$ and the friction due to the collisions with a buffer gas. When the electric field is uniform and weak, the ions reach a steady-state velocity $\left(v_{D}\right)$ and take different times $\left(t_{D}\right)$ to cross a drift cell of length $L$. The resulting mobility $\left(K=V_{D} / E\right)$ is mainly dependent on the structure of the gaseous compounds and it gives access to a molecular and conformation descriptor known as collision cross section (CCS or $\Omega$ )[1-3].

Along with the application as free-standing device, ion mobility spectrometry is now routinely coupled with mass spectrometry (IMS-MS) [4, 5] and the release of commercial instruments has contributed progresses in multi-dimensional separation. Using ion mobilities and CCS for the characterization of complex mixtures is fast becoming common practice in many "-omic" areas, to obtain information on the three-dimensional structure, as well as to infer biomolecules folding [6-8].

The drift tube ion mobility mass spectrometers (DTIMS) have been established for the longest time. $[4,9]$ In contrast with DTIMS that allows a direct determination of the CCS using the measured experimental ion mobilities, non-uniform electric field drift cells such as the traveling wave (TWIMS) and the trapped (TIMS) ion mobility cells, usually use a calibration procedure, with reference ions of known CCS or reduced mobility to determine CCS [10, 11]. Many macromolecules such as polymers, peptide mixtures or polysaccharides are commonly used as reference compounds for CCS determination [12-15]. However, the choice of the suitable calibrant is sometimes tricky and several factors must be considered. For example, it is recommended to match the chemical nature, the mass range and charge state of the analyte and the calibrant [16]. Richardson et al. [17] theorized that in TWIMS, because of velocity relaxation effects, the time-mobility calibration also depends on the ion mobility- $\mathrm{m} / \mathrm{z}$ trends. Haler et al. [18] suggested that apparent densities matter. In order to obtain transferrable calibration curves, and to test these hypotheses, it is thus important to have mobility and CCS values of series of compounds having different apparent densities and mobility- $\mathrm{m} / \mathrm{z}$ trends. Moreover, ion mobility measurements should be supported by an evaluation of the influence of instrumental settings on the CCS of the investigated compounds. Experimental conditions in the pre-IMS region could indeed influence ion conformation and hence the accuracy of the results. Reference compounds derived from peptides can be affected by collision induced unfolding (CIU) processes prior or into the IMS cell and undergo changes in their conformation and CCS $[13,19]$. Besides, a significant fragmentation of the calibrant due to activation after the ion mobility cell could lead to fragment ions with different $\mathrm{m} / \mathrm{z}$ value generating inconveniences during the ion mobility peak identification [20].

To develop new reference materials, we previously performed IMS-MS measurements on phosphoric acid cluster anions, in nitrogen gas [21]. Organic and inorganic salts easily form cluster ions by direct infusion in an electrospray ionization source (ESI). Such clusters exist with a large charge state range and have long been used as mass calibrants [22-24]. As phosphoric acid contains both proton donor and acceptor sites, its cluster ions are maintained by non-covalent interactions akin to those found in biological molecules susceptible to undergo collision-induced unfolding. Phosphoric acid cluster ions have been used on TWIMS ion mobility mass spectrometers to obtain experimental parameters that reduce fragmentation and retain hydrogen bonds [21]. Recently, using a Tofwerk DTIMS instrument 
operated in $\mathrm{N}_{2}$ at $\sim 305 \mathrm{~K}$ we determined values of $\mathrm{K}_{0}$ and CCS (termed ${ }^{\mathrm{DT}} \mathrm{CCS}_{\mathrm{N}_{2}}$ ) for twentysix singly, doubly and triply charged phosphoric acid cluster anions [25]. These clusters were used as reference compounds for calibration and CCS determination on a TWIMS drift cell $\left({ }^{\mathrm{TW}} \mathrm{CCS}_{\mathrm{N}_{2}}\right)$. Accuracy tests on ions derived from polyalanine, dextran and the hexakis(fluoroalkoxy)phosphazine at $\mathrm{m} / \mathrm{z} 602$ when the TWIMS was calibrated with phosphoric acid cluster anions, evidenced a bias of 9-11 $\AA^{2}$ (between the CCS values in $N_{2}$ $\left({ }^{\mathrm{TW}} \mathrm{CCS}_{\mathrm{N}_{2}}\right)$ and and the published ${ }^{\mathrm{DT}} \mathrm{CCS}_{\mathrm{N} 2}$ values [25].

Here, we determined new $\mathrm{K}_{0}$ and ${ }^{\mathrm{DT}} \mathrm{CCS}_{\mathrm{He}}$ values for phosphoric acid cluster anions with charge states between 1- and 4- using an Agilent DTIMS operated in He at $296 \mathrm{~K}$. In addition, we monitored the ${ }^{\mathrm{DT}} \mathrm{CCS}_{\mathrm{He}}$ values of phosphoric acid cluster ions for different pre- and post-IMS voltage gradients on the 6560 IMS-Q-TOF. We observed how different pre- and post-IMS settings led to changes in the ion mobility and mass spectra and how their $\mathrm{K}_{0}$ and ${ }^{\mathrm{DT}} \mathrm{CCS}_{\mathrm{He}}$ values were affected.

\section{MATERIALS AND METHODS}

\section{Sample preparation}

Phosphoric acid (for analysis, $85 \%$ solution in water, density 1.680) was purchased from Acros Organics (Fisher Scientific France, Illkirch, France). Deionized water (18 $\mathrm{M} \Omega$ ) was produced by a Milli-Q apparatus (Millipore, Bedford, MA, USA). Acetonitrile was purchased as LC-MS grade from VWR (Fontenay-sous-bois, France). Phosphoric acid samples were prepared at a concentration of $5 \mathrm{mM}$ using a volume of $0.035 \%$ of the initial phosphoric acid solution in water/acetonitrile $(50 / 50 \mathrm{v} / \mathrm{v})$. This $5 \mathrm{mM}$ solution of phosphoric acid was enriched with 50 $\mu \mathrm{M}$ ammonia to perform the collision induced experiments (CID) on the ammonia adducts of multiply charged phosphoric acid cluster anions. Ammonium hydroxide solution $29.3 \% \mathrm{NH}_{3}$ was from Sigma Chemical (St. Louis, MO, USA).

The mixture of hexakis-(fluooalkyloxy)-phosphazines (Tuning Mix, Agilent Technologies) was diluted to 1:4 with 95\% acetonitrile in water and was used either alone or in mixture with phosphoric acid.

\section{Drift tube ion mobility mass spectrometry measurements}

Uniform electric field drift tube ion mobility mass spectrometry (DTIMS-MS) measurements were performed and replicated with an interval of eight months, on an Agilent 6560 (Santa Clara, CA). The instrument couples a drift tube to a quadrupole time-of-flight mass spectrometer (IMS-QTOF) and it has been described in detail elsewhere [26].

The samples were directly infused at a flow rate of $3 \mu \mathrm{L} / \mathrm{min}$ in an electrospray ionization source (ESI) operated in the negative ion mode. The generated anions were transmitted and accumulated by two stages of ion funnels and separated in a drift tube with a length of $78.1 \pm$ $0.2 \mathrm{~cm}$. The standard uncertainty on the length takes into account the possible edge effects of the electric field. This was estimated from the study by Stow et al. [27] which determined the effective length of three other Agilent 6560 DTIMS instruments operated in $\mathrm{N}_{2}$ and under higher voltages to be $78.24 \pm 0.16 \mathrm{~cm}$. Ion mobility separations were performed using helium (He) as buffer gas. An in-house modification to the pumping system allows faster (a few minutes) equilibration of the pressures for the helium measurements: a second Tri-scroll 800 pump (Agilent) was connected to the source region (with an Edwards SP16K connected to the front pumping line), while the original Tri-scroll 800 pump is connected to the Q-TOF region. 
To ensure appropriate pressure differentials on either side of the drift tube for collision cross section determination, the pressures were set to 3.76 Torr in the drift tube and 3.47 Torr in the trapping funnel before the flow controller was turned on. For all measurements, the flow controller was turned on, this resulted in a pressure of the gas in the drift tube of $3.894 \pm$ 0.010 Torr (measured using an Agilent CDG-500 capacitance diaphragm gauge), and $3.63 \pm$ 0.01 Torr in the trapping funnel. The correct gas flow and pressure difference in these regions were maintained through a feedback system (640B, MKS Instruments) based on the IMS pressure measured at the rear of the drift tube. We found that adjusting the helium pressure differential with the mass flow controller active was not robust enough to ensure $100 \%$ helium in the drift tube (for nitrogen measurements, this is not critical). The instrument was operated, with covers open, in a well air-conditioned room and the temperature of the drift cell was monitored by a K-type thermocouple (Omega Engineering). The estimated mean value was $296.6 \mathrm{~K}$ with a standard deviation of $0.5 \mathrm{~K}$.

Table S1 provides a detailed list of the parameters used for all the measurements on phosphoric acid cluster anions. These conditions were optimized by Gabelica et al. to gather mainly the native state $7+$ of ubiquitin on the same apparatus and the signs were reversed for the negative ion mode [28]. Both folded proteins and phosphoric acid clusters are maintained by hydrogen bonds in the gas phase. The enthalpy requirement for unfolding of gas phase ubiquitin ions has been evaluated around $0.4 \mathrm{eV}$ [29]. This energy is lower than the enthalpy estimated for the dissociation of one phosphoric acid molecule from cluster ions $\left[\left(\mathrm{H}_{3} \mathrm{PO}_{4}\right)_{n}-\right.$ $\mathrm{H}]^{-}$with one to six phosphoric acid molecules, and which was calculated to be around $1 \mathrm{eV}$ [21]. Furthermore, the dissociation energy of one phosphoric acid molecule decreases with increasing aggregation number. The energy barrier for protein unfolding was thus expected to be in the same order of magnitude as the declustering of phosphoric acid clusters.

We chose to probe the influence of two different conditions based on different values of the voltage applied on the fragmentor, which represents the part of the ESI source that speeds up ions from the glass capillary to the high pressure funnel resulting in one of the principal cause of in-source collision induced dissociation (in-source CID). Fragmentor voltages of $300 \mathrm{~V}$ or $350 \mathrm{~V}$ (which are here equivalently named "soft") and $600 \mathrm{~V}$ ("harsh") were used. These values corresponded to a potential difference established between the fragmentor and the entrance of the high pressure funnel of 40 or $90 \mathrm{~V}$ and $340 \mathrm{~V}$, respectively.

To obtain the reduced mobility values $\left(K_{0}\right)$ and determine CCS values, we used the stepped field (also called multi-field) method. Five different values of the electric field applied in the drift tube were imposed for 1 to 3 min each. The applied electric field $E$ were 5.009, 6.280, $7.561,8.841,10.122 \mathrm{~V} / \mathrm{cm}$, in helium. Taking the pressure and temperature into account, the gas number density $N$ was $1.26810^{23} \mathrm{~m}^{-3}$, and this amounted to reduced electric field strengths $(E / N)$ of 4 to $8 \mathrm{Td}$.

The time values $(t)$ obtained from the extracted ion mobility spectra (EIM) (also called arrival time distributions (ATD)) of the experiments at different electric fields were then fitted using a linear regression of time vs. the reciprocal of the field strength $(1 / E)$. Drift times were collected picking the apex of the peak of the intact phosphoric acid cluster anions. This procedure allowed to retrieve, from the intercept, the time spent by the ions outside the drift cell $\left(t_{0}\right)$ and the slope from which the value of the ion mobility $(K)$ was inferred, according to the Eq.1.

$$
t=\left(\frac{L}{K}\right) \cdot \frac{1}{E}+t_{0}
$$


We will refer to $t$ as the drift time, although it is often called arrival time because of the nonnull value of $t_{0}$. The $K$ values were then converted to a reduced ion mobility $K_{0}$ to scale the ion mobility into the number gas density value $N_{0}$ at standard pressure and temperature ( $p_{0}$ and $T_{0}, 760$ Torr and $273.15 \mathrm{~K}$, respectively) (Eq. 2). We determined the ${ }^{\mathrm{DT}} \mathrm{CCS}$ values in He using to the low-field limit equation (Eq. 3 ) where $e$ is the elementary charge, $k$ the Boltzmann constant, $z$ the charge number and $\mu$ the reduced mass of the ion and helium gas [30].

$$
\begin{array}{r}
K_{0}=\frac{N}{N_{0}} K=\frac{p}{p_{0}} \frac{T_{0}}{T} K \\
{ }^{D T} C C S=\frac{\sqrt{18 \pi}}{16} \frac{e}{\sqrt{k T}} \frac{z}{\sqrt{\mu}} \frac{1}{N_{0}} \frac{1}{K_{0}}
\end{array}
$$

For the post-IMS transmission, we used the two experimental tunings described thoroughly by Gabelica et al. [28] that were developed using as benchmark the ammonium-bound bimolecular G-quadruplex, which easily undergoes ammonia loss. These tunings consist in different gradients of DC voltages between the exit of the ion mobility cell and the TOF analyser. We will refer to the softest gradient as "soft" and the other one as "harsh", although both tunings are gentle. A complete list of the applied voltages forming the gradients is presented in Table S1.

\section{Data analysis}

The ion mobility spectra acquired by the Agilent instrument were extracted through the Agilent IM-MS browser (version B.08.00, build 8.0.815.0). Classical linear regression was based on least squares minimization. We obtained the linear regressions of five points with uncertainties on the slope and intercept using the classical least squares regression analysis in OriginPro 2018 (version b.9.5.0.193) or in a Microsoft Excel spreadsheet (2016 MSO 16.0.4266.1001 64 bits). An example of linear regression with residual analysis and associated uncertainties with 95\% level of confidence is given in figure S1 for the P\#8- phosphoric acid cluster anion $\left(\left[\left(\mathrm{H}_{3} \mathrm{PO}_{4}\right)_{8}-\mathrm{H}\right]^{-}\right.$. In all cases, the determination coefficient $\mathrm{R}^{2}$ was higher than 0.995 . The slopes ranged from 6.6 to $13.6 \mathrm{~s} \mathrm{~V} \mathrm{~cm}^{-1}$ with a maximum relative standard deviation of $5.4 \%$. The mean relative standard deviation for the slopes was $0.7 \%$.

The uncertainty on the ${ }^{\mathrm{DT}} \mathrm{CCS}_{\mathrm{He}}$ values was evaluated according to the current GUM guideline. [31] First, a type A evaluation on collision cross sections obtained from replicates $(n)$ provided the experimental standard deviation $(\sigma)$ and the experimental standard deviation of the mean (u) (calculated as $\sigma / \sqrt{n}$ ). Second, we also performed an estimation of the uncertainty on CCS with the propagation of errors from different components such as pressure, temperature, slope and length of the drift tube. As a type B standard uncertainty is derived from the probability that an event will occur, we performed a Monte Carlo simulation using the Crystal Ball add-in for Microsoft Excel (Oracle ${ }^{\circledR}$, version 11.1.2.4.850) on the ${ }^{\mathrm{D} T} \mathrm{CCS}(\mathrm{He})$ of the P\#8cluster anion $\left(\left[\left(\mathrm{H}_{3} \mathrm{PO}_{4}\right)_{8}-\mathrm{H}\right]^{-}\right)$. We obtained a normal distribution and the standard deviation. A similar approach has been applied by Stow et al. [27] to propagate errors on the arrival times due to the uncertainty of the voltage $\Delta V$. Errors were propagated by applying a uniform distribution both for the drift tube length and a normal distribution for the drift tube pressure and temperature. The uncertainties were estimated to $\pm 0.2 \mathrm{~cm}$ for the tube length $(78.1 \mathrm{~cm}$, relative uncertainty $0.3 \%), \pm 0.5 \mathrm{~K}$ for the temperature $(296.6 \mathrm{~K}$, relative uncertainty $0.2 \%), \pm$ 
0.010 Torr for the pressure (3.894 Torr, relative uncertainty $0.3 \%$ ). A triangular distribution was used for the slope $(\mathrm{L} / \mathrm{K})$ using a maximum deviation of $\pm 0.5 \mathrm{~s} \mathrm{~V} \mathrm{~m}^{-1}$ on the $10.3 \mathrm{~s} \mathrm{~V} \mathrm{~m}^{-1}$ slope obtained from the $\mathrm{P \# 8}$ - cluster anion. This $\pm 0.5 \mathrm{~s} \mathrm{~V} \mathrm{~m}^{-1}$ value was the maximum standard deviation observed for the slope for all ions.

\section{Tandem mass spectrometry measurements}

Tandem mass spectrometry measurements were performed on a Synapt G2 (Waters Corp., Manchester, UK). The $5 \mathrm{mM}$ solution of phosphoric acid, supplemented with $50 \mu \mathrm{M}$ of ammonium hydroxide was infused using the sample pump at a flow rate of $5 \mu \mathrm{L} / \mathrm{min}$ to the ESI source coupled with the instrument and operated in negative ion mode. Conditions in the electrospray were: capillary voltage $2.7 \mathrm{kV}$, sampling cone voltage $60 \mathrm{~V}$, extraction cone voltage $2 \mathrm{~V}$, source temperature $90^{\circ} \mathrm{C}$, desolvation temperature $250^{\circ} \mathrm{C}$, desolvation gas flow $500 \mathrm{~L} / \mathrm{h}$, source gas flow $20 \mathrm{~mL} / \mathrm{min}$. Collision-induced dissociation (CID) experiments were performed by selecting the monoisotopic ion of $\mathrm{NH}_{3}$ adducts for sample phosphoric acid cluster ions in the quadrupole. We chose to fragment the selected clusters in the trap cell by applying a collision voltage of 5 to $15 \mathrm{~V}$. A list of other relevant experimental parameters used to perform measurement on the Synapt G2 are gathered in Supplementary Table S2. The raw data were extracted using MassLynx ${ }^{\mathrm{TM}}$ (4.1 version).

\section{RESULTS AND DISCUSSION}

\section{Drift tube ion mobility mass spectrometry of phosphoric acid cluster anions}

Solutions of $5 \mathrm{mM}$ phosphoric acid were investigated by DTIMS under four different combinations of experimental pre-IMS and post-IMS conditions. Figure 1 shows colour maps of $\mathrm{m} / \mathrm{z}$ vs drift time from the electrospray-generated ions in the negative ion mode for two different sets of conditions in the ESI source (soft and harsh pre-IMS) and very soft post-IMS conditions, with a drift field of $5 \mathrm{~V} \mathrm{~cm}^{-1}$ and helium as drift gas. The maps clearly indicate the formation of singly and multiply charged clusters $\left[\left(\mathrm{H}_{3} \mathrm{PO}_{4}\right)_{n}-\mathrm{zH}\right]^{z-}$ covering an $\mathrm{m} / \mathrm{z}$ range of $300-3100$ and well separated according to their charge states in diagonal lines, each corresponding to a different charge state up to 8-. The assignment of the charge for each line was based on the isotopic pattern of the extracted mass spectra. In addition to the pure phosphoric acid cluster ions, the mass spectra also included peaks of significant intensity corresponding to adducts formed by clusters with the residual ammonia, sodium and potassium present as contaminant in the ion source. While sodium or potassium adducts $\left[\left(\mathrm{H}_{3} \mathrm{PO}_{4}\right)_{n}-z \mathrm{H}+x \mathrm{Na}\right]^{(z-x)-}$ or $\left[\left(\mathrm{H}_{3} \mathrm{PO}_{4}\right)_{n}-z \mathrm{H}+x \mathrm{~K}\right]^{(z-x)-}$ were present in low abundance for all the charge states, ammonia adducts $\left[\left(\mathrm{H}_{3} \mathrm{PO}_{4}\right)_{n}-z \mathrm{H}+x \mathrm{NH}_{4}\right]^{(2-x)-}$ were observed only for multiply charged states. The number of $\mathrm{NH}_{4}{ }^{+}$and $\mathrm{Na}^{+}$(or $\mathrm{K}^{+}$) included in the clusters appeared to be different depending on the charge state, with up to two cations for the doubly charged, three for the triply charged ions and four for quadruply charged clusters (Figure S2).

Figure 1a shows the presence of an additional population of signals at lower drift times, compared to figure $1 \mathrm{~b}$, that we annotated as metastable species. These signals correspond to ions with high charge states, and formed an appendix to the main more intense signals. Similar phenomena exist in the ion mobility spectra of several ionic liquids [32, 33] and iodide salt cluster ions [34] obtained by a differential mobility analyser (DMA). The most intense signals include intact cluster ions as well as the product of neutral and ion evaporation events of higher charge state cluster ions that occur between the DMA and the detection system [35]. This additional population of signals was not present when harsher conditions were used in 
the ESI source, pointing out that these metastable species are formed during the electrospray process and maintained up to the IMS when very soft pre-IMS conditions are applied, but fragment during or after the IMS even with our very soft post-IMS conditions. We observed that the absolute intensities of these metastable ions decreased by a factor of 1.6 when the electric field in the ion mobility cell was $10 \mathrm{~V} \mathrm{~cm}^{-1}$ compared to the lowest values of $5 \mathrm{~V} \mathrm{~cm}^{-1}$. The other phosphoric acid clusters (that are observed in both ESI conditions) were 15 times more intense than the metastable population and their absolute intensities did not change with the variation in electric field (Figure 2). The decrease in the absolute intensities of metastable ions pointed towards a possible increase in fragmentation yields as the ions go faster through the drift tube. However, as reported elsewhere [35], dissociation events taking place during the mobility separation should be signalled by the presence of extended streaks at an intermediate mobility of the parent and the fragmentation product. Being for now uncertain as to the attribution of what we named metastable species, we chose to concentrate our attention on the main intense population of cluster ions that were reproducibly observed in all experimental conditions. 


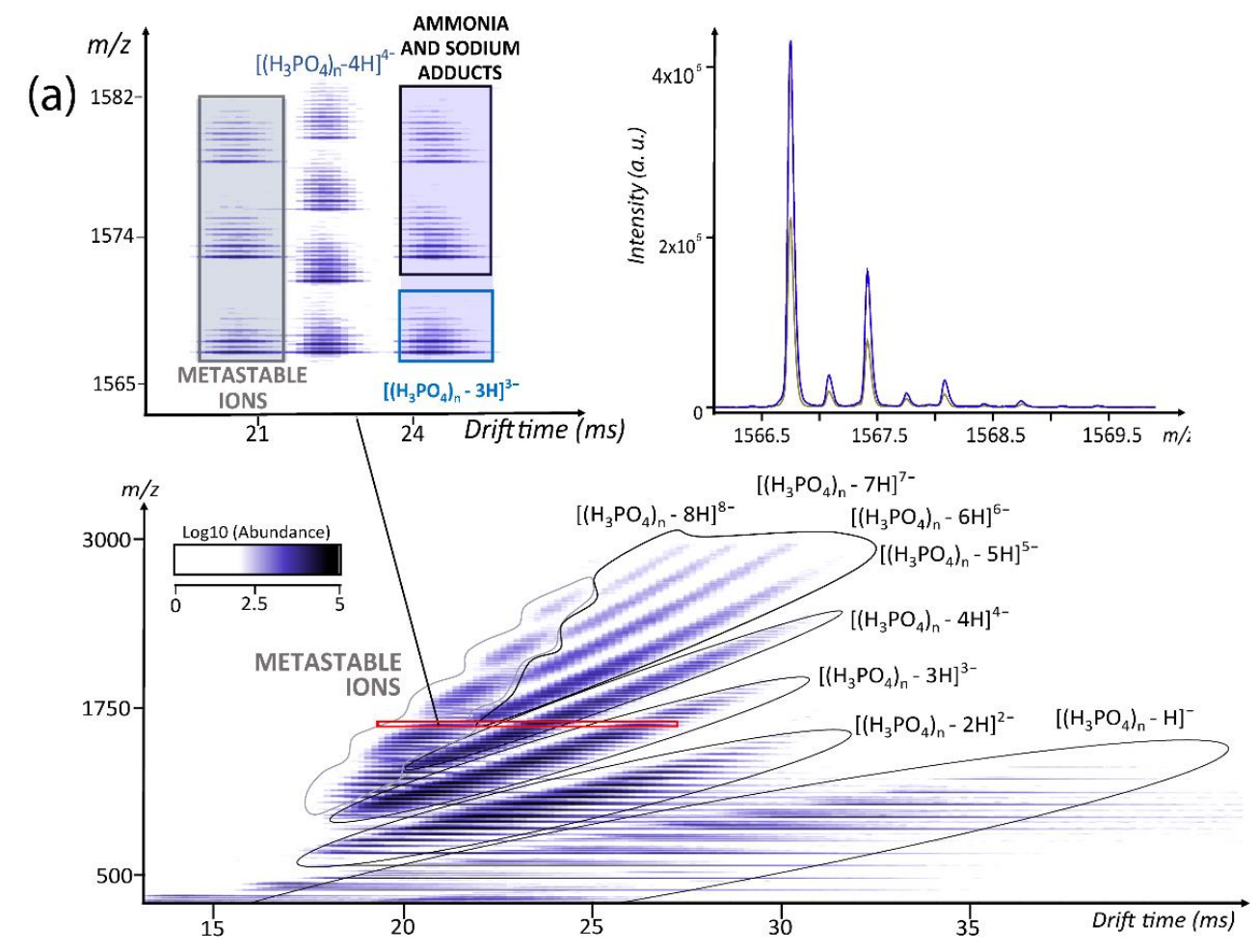

(b)

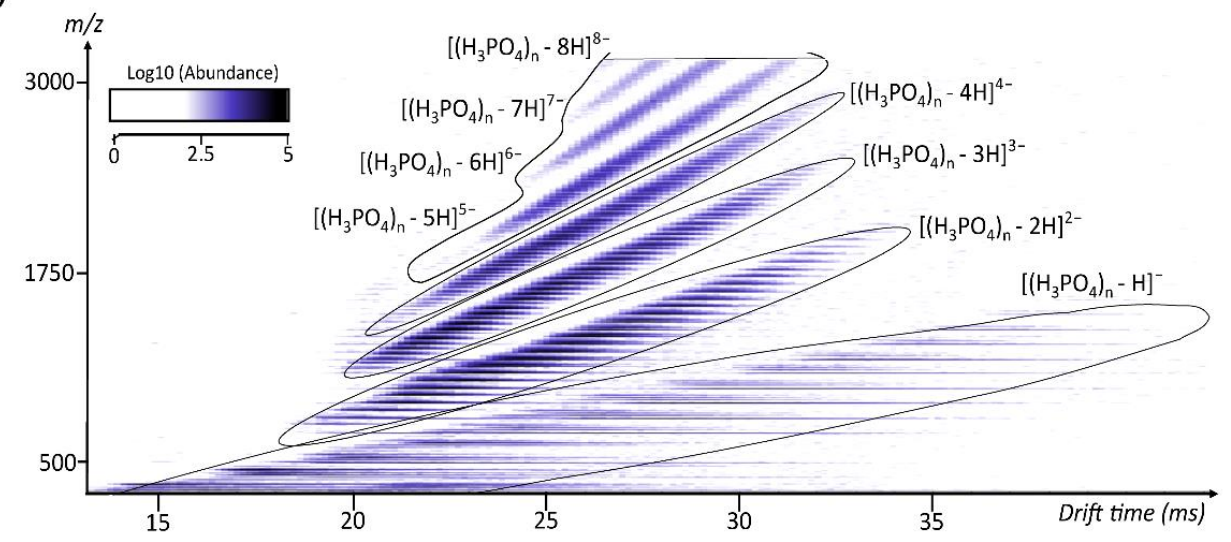

Figure 1. ESI DTIMS in negative ion mode of a $5 \mathrm{mM}$ solution of phosphoric acid: colour maps of $\mathrm{m} / \mathrm{z}$ vs drift time (ms) obtained a) in soft pre-IMS and soft post-IMS conditions and b) in harsh pre-IMS conditions and soft post-IMS conditions at $10 \mathrm{~V} / \mathrm{cm}$ in the drift tube. The inset on the left shows an enlarged area where two populations of triply charged ions are seen framing quadruply charged ions. We named these two populations metastable ions (grey) and main phosphoric acid cluster ions (blue). The extracted mass spectra of the metastable and main populations around 21 and 24 ms respectively showed the same $m / z$ values, corresponding to the isotopic distribution of $\left[\left(\mathrm{H}_{3} \mathrm{PO}_{4}\right)_{48}-3 \mathrm{H}\right]^{3-}$ (inset on the right in (a)). 


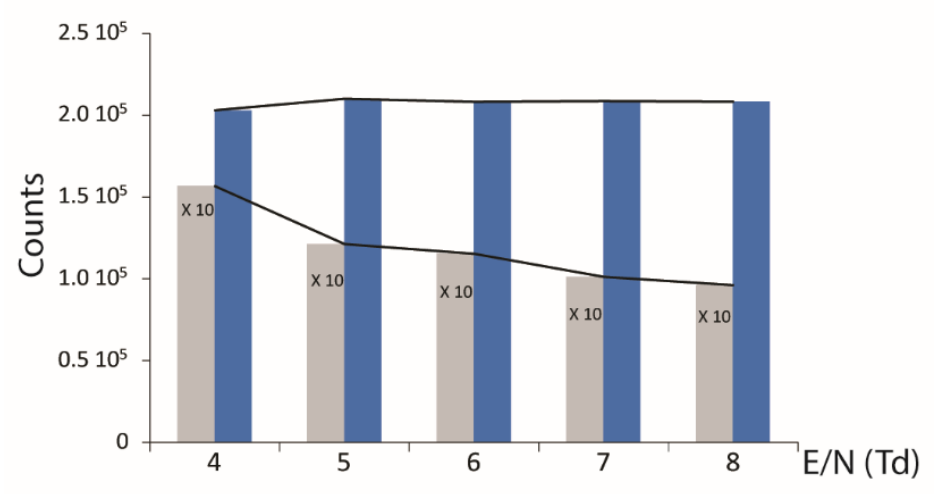

Figure 2. Absolute intensities of metastable ions (grey) multiplied 10 times and absolute intensities of the main stable (blue) phosphoric acid cluster ions present in soft pre-IMS/ soft post-IMS conditions as a function of the reduced electric field (Td) applied in the ion mobility cell during the multi-field measurements. Black lines are only a guide for the eyes.

When dissociation processes occur during the post-IMS transmission towards the TOF analyser, the extracted ion mobility (EIM) spectra, also called arrival time distribution (ATD), of a given $\mathrm{m} / \mathrm{z}$ corresponding to a phosphoric acid cluster with aggregation number $n$, $\left[\left(\mathrm{H}_{3} \mathrm{PO}_{4}\right)_{n}-\mathrm{zH}\right]^{z^{-}}$(further noted $\left.\mathrm{P \#} n^{2-}\right)$, may display several peaks. The presence of more than one peak for each ion should not be attributed to different conformations, but to ion mobility signals of larger phosphoric acid clusters $(n+1, n+2$, etc.) that dissociate after the ion mobility cell due to ion and neutral evaporation processes. In a previous work, we described extensively the method to assign the ion mobility peak to the correct phosphoric acid cluster ion [21]. This consists in overlaying and comparing the EIM of clusters with adjacent aggregation numbers, which are possible precursor ions. A peak that is present only in the EIM of the investigated cluster and not in the EIM of larger ones is then assigned to the intact ion. As an example, Figure 3a shows the overlay of EIM for phosphoric acid clusters with $\mathrm{m} / \mathrm{z}$

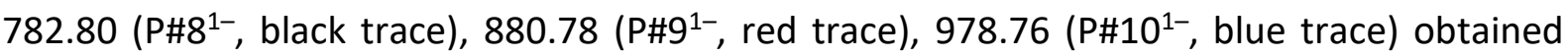
from the measurements in helium at a drift field of $5 \mathrm{~V} \mathrm{~cm}^{-1}$. A drift time value of $26.39 \mathrm{~ms}$ was attributed to the intact singly charged cluster P\#8- (black line). The signals at longer drift time ( 28.05 and $29.72 \mathrm{~ms}$ ) correspond to the amount of P\#8- formed by neutral evaporation events of $\mathrm{H}_{3} \mathrm{PO}_{4}$ molecules from the clusters $\mathrm{P} \# 9^{-}$and $\mathrm{P} \# 10^{-}$after the ion mobility cell. Moreover, during the process of assignment of the drift times, one must consider that for a given $\mathrm{m} / \mathrm{z}$ value, higher-order multimers could exist. Figure 3 shows the full EIM spectra of the $\mathrm{m} / \mathrm{z}$ values $782.80,880.78,978.76$ corresponding to the singly charged clusters P\#8-, P\#9-, $\mathrm{P} \# 10^{-}$also contained the mobility peaks of the doubly charged phosphoric acid ions $\mathrm{P} \# 16^{2-}$, $\mathrm{P \#} 18^{2-}$ and $\mathrm{P} \# 20^{2-}$.

Overlaying different EIM spectra is useful whenever one wants to avoid a wrong assignment of the drift time value. In fact, some clusters may completely be dissociated after the ion mobility separation. On figure 3a, the signals at lower drift times in the EIM of $\mathrm{m} / \mathrm{z} 782.8$ (black trace) include a broad peak at $21.35 \mathrm{~ms}$ which appeared with the same drift time value in the EIM of $\mathrm{m} / \mathrm{z} 880.78$ (red trace) with a larger intensity. We therefore could not attribute

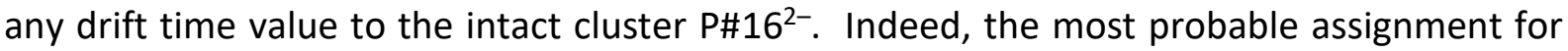
the peak at 21.35 ms corresponded to the neutral evaporation process of $\mathrm{H}_{3} \mathrm{PO}_{4}$ molecules 
from the doubly charged cluster $\mathrm{P} \# 18^{2-}$ after its mobility separation and no drift time could be assigned to an intact $\mathrm{P} \# 16^{2-}$.

As the amount of the intact cluster ions depends on experimental conditions, we used the method of overlaying the EIM relative to a given phosphoric acid cluster and its potential precursor ions to monitor how pre- and post-IMS experimental settings affect the abundance of intact and precursor clusters. Figure 3 shows the overlaid EIM at a drift field of $5 \mathrm{~V} \mathrm{~cm}^{-1}$ in

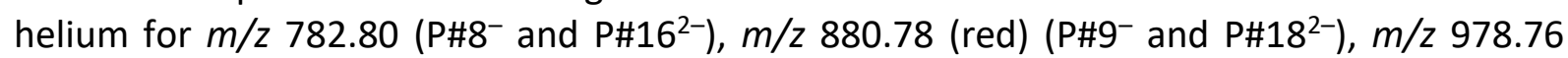
(blue) (P\#10- and $\mathrm{P} \# 20^{2-}$ ) and $\mathrm{m} / \mathrm{z} 1027.75$ (magenta) $\left(\mathrm{P} \# 21^{2-}\right)$ under the four experimental conditions corresponding to (a) harsh pre-IMS/ soft post-IMS, (b) harsh pre-IMS/harsh postIMS, (c) soft pre-IMS/ soft post-IMS and (d) soft pre-IMS/harsh post-IMS.

Comparing panel (a) with (c) and panel (b) with (d) in Figure 3, which differ only in the pre-IMS conditions, reveals that soft pre-IMS ( $c$ and $d$ ) leads to a higher proportion of larger doubly charged cluster anions This is also visible is Figure S3 that overlays the EIM of $m / z 880.8$ in all experimental conditions. The comparison of the couples formed by panels (a) with (b) and (c) with (d), in Figure 3, reveals the effect of different post-IMS settings on the amount of cluster ions that undergo dissociation after the ion mobility cell. The peak positions for harsh postIMS transmission were shifted to lower drift times because the higher speed of ions between the ion mobility and the TOF analyser led to lower to values (see also Figure S3). Peaks were better resolved with smaller peak widths due to a lower diffusion time in the post-IMS area. The overlaid EIM obtained with the harsh post-IMS transmission settings (panel $b$ and $d$ )

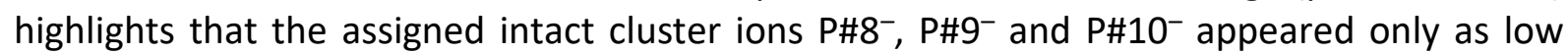
intensity shoulder peaks and that some dissociation occurred for the doubly charged clusters

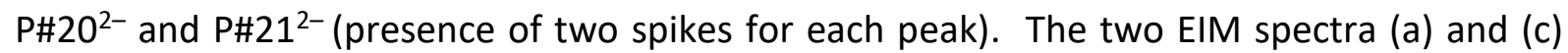
obtained with the soft post-IMS transmission settings show larger relative intensities of intact

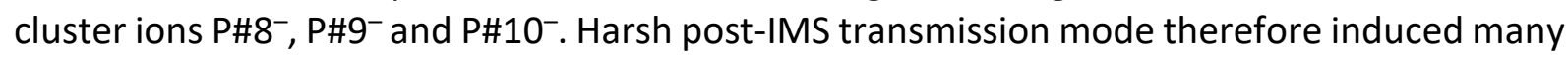
dissociations of hydrogen bonds after the ion mobility cell. The soft post-IMS transmission also presented some dissociation processes, but in a lower proportion. The attribution of ion mobility signals was always easier and more reliable with soft post-IMS transmission settings. For multiply charged cluster anions, the amount of dissociation was difficult to estimate as the signals of adjacent cluster ions overlapped. However, in most cases, we hypothesized the apex of the signals of the multiply charged cluster anions to be largely attributable to the intact cluster ions. Indeed, here as in our previous study [25], we observed that the relative proportion of dissociated precursor ions to intact cluster ions tended to decrease with the aggregation number. For several cluster anions, however, no reliable signal attribution could

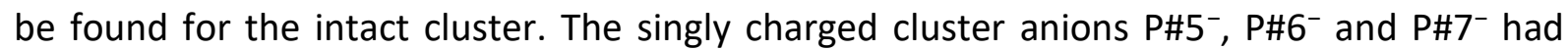
signals which overlapped the signals of unresolved multiply charged ions, and the signals of several ions, as the $\mathrm{P} \# 16^{2-}$ in Figure 3, we entirely attributed to fragmented doubly charged precursor ions. Also, in cluster ions with an aggregation number close to the charge state change (aggregation numbers 14 to 16 between charge states 1 - and 2- and aggregation numbers 33 to 36 between charge states 2 - to $3-$ ), the intensities and signal over noise ratio were too low for any reliable attribution. Note that when the precursor ions are of the same charge state as the resulting fragment ion, they are expected at a drift time slightly higher than that of the intact cluster in the EIM. For ion evaporation processes, precursor and fragments have different charge states so that their drift times are more different. For example, a triply charged ion resulting from the ion evaporation of a "metastable" quadruply charged cluster, should appear with a drift time similar to that of quadruply charged ions, 
while the true and intact, triply charged should appear as a peak in the zone of the triply charged species of the EIM spectra.
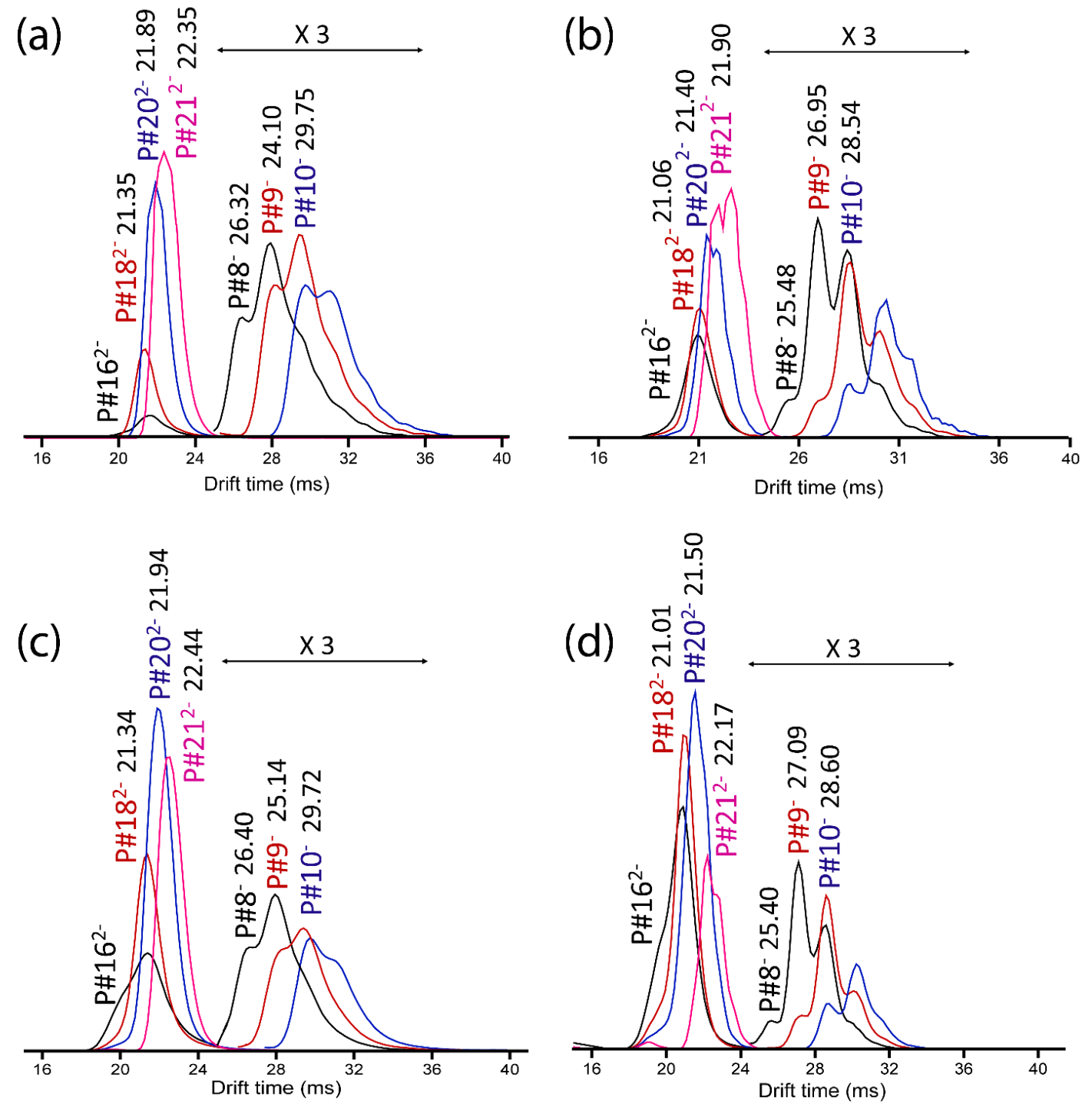

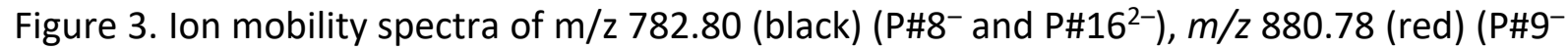

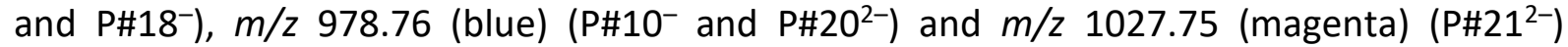
extracted at four different combinations of experimental conditions applied in the pre-IMS and post-IMS: (a) harsh pre-IMS/ soft post-IMS, (b) harsh pre-IMS /harsh post-IMS, (c) soft pre-IMS / soft post-IMS and (d) soft pre-IMS/harsh post-IMS tunings are shown. The EIM spectra presented above were recorded at a drift field of $5 \mathrm{~V} \mathrm{~cm}^{-1}$ in the ion mobility region. The omitted $y$ axes correspond to the signal intensity in arbitrary units normalized to the highest peak on display.

As ammonium and sodium adducts were present, we wanted to assess whether they could be potential precursor ions to pure phosphoric acid cluster ions. While the loss of $\mathrm{Na}^{+}$from an $\left[\left(\mathrm{H}_{3} \mathrm{PO}_{4}\right)_{n}-z \mathrm{H}+x \mathrm{Na}\right]^{(2-x)-}$ adducts is highly improbable as it would lead to the formation of a phosphoric acid cluster ions with a higher charge state, the loss of neutral $\mathrm{NH}_{3}$ from an $\left[\left(\mathrm{H}_{3} \mathrm{PO}_{4}\right)_{n}-z \mathrm{H}+x \mathrm{NH}_{4}\right]^{(z-x)-}$ was more likely. If ammonia adducts were precursors to pure deprotonated phosphoric acid clusters, fragmentation of ammonia adducts could lead to possible ambiguities in the drift time assignment, as their respective drift times were nearly identical (inset in figure 1a). In order to figure out how ammonia adducts dissociate, we 
performed collision induced experiments (CID) on several doubly and triply charged ammonia adducts chosen among the most intense species in the mass spectra. Fragmentations were carried out, after selection in the quadrupole and in the trap cell of a Waters Synapt G2 ion mobility mass spectrometer by applying a collision voltage of $5 \mathrm{~V}$. The CID spectrum obtained for the triply charged adduct $\left[\left(\mathrm{H}_{3} \mathrm{PO}_{4}\right)_{39}-4 \mathrm{H}+\mathrm{NH}_{4}\right]^{3-}(\mathrm{m} / z$ 1278.37) (Figure S4) showed two preferred fragmentation pathways, and all adducts acted in a similar way. One fragmentation pathway corresponded to the loss of neutral molecules of $\mathrm{H}_{3} \mathrm{PO}_{4}$ to form triply charged ammonia adducts with lower aggregation numbers. The other fragmentation pathway involved the loss of singly charged phosphoric acid cluster anions with small aggregation numbers leaving as fragment ions doubly charged ammonia adducts. The neutral loss of $\mathrm{NH}_{3}$ from the precursor ion was detected only in very low intensity: the relative abundance of the triply charged phosphoric acid cluster fragment $\left[\left(\mathrm{H}_{3} \mathrm{PO}_{4}\right)_{39}-3 \mathrm{H}\right]^{3-}$ represented less than $1 \%$ of the total intensity of all fragment ions. The ionic interactions formed by ammonia in the adducts could thus be considered as strong enough to ensure its retention in the clusters and ammonia adducts could be excluded as potential precursor ions of pure deprotonated phosphoric acid cluster ions.

\section{Effect of experimental conditions on ${ }^{\mathrm{DT}} \mathrm{CCS}_{\mathrm{He}}$ values}

To check the effect of different pre-IMS parameters on CCS values, we first performed multifield measurements on the calibrants of the Agilent tuning mix, for which ${ }^{\mathrm{DT} C C \mathrm{C}_{\mathrm{He}} \text { were }}$ published in 2017 [36]. Measurements were repeated eight months apart and replicated for different pre-IMS conditions using solutions of tuning mix either alone or in a mixture with phosphoric acid, with harsh post-IMS conditions. Figure 4 (and Table S3) presents the ${ }^{{ }^{T} T} \mathrm{CCS}_{\mathrm{He}}$ values obtained for the tuning mix in our experiments and the standard deviation for the total sets of experiments $(n=6)$ along with the ${ }^{\mathrm{DT}} \mathrm{CCS}_{\mathrm{He}}$ values from Anal. Chem 2017 [36], represented on the right of each graph with its standard deviation. Regardless of the change in pre-IMS conditions, considering a $90 \%$ level of confidence $(\approx 2 \sigma)$ all tuning mix ions presented ${ }^{\mathrm{DT}} \mathrm{CCS}_{\mathrm{He}}$ values that were consistent with the Anal. Chem 2017 [36] values. The absence of any significant bias between previously published values and our determined values ensured the reliability of instrument performances for this study. In fact, the standard deviation of six replicates on ${ }^{\mathrm{DT}} \mathrm{CCS}_{\mathrm{He}}$ values obtained with different instrumental parameters ranged between 0.3 to $1.2 \AA^{2}$ ( 0.3 to $0.5 \%$ relative standard deviation (RSD)). These standard deviations were lower than the ones published in Anal. Chem 2017 which were obtained from three independent replicates ( 1.3 to $1.9 \AA^{2}$ i.e. 0.6-1.2\% RSD). These standard deviation values are not far from the relative standard deviations of $0.22 \% \operatorname{RSD}(n=36)$ reported in $\mathrm{N}_{2}$ [27] or the $0.7 \% \operatorname{RSD}(n=5)$ reported in helium in the positive ion mode [37]. 


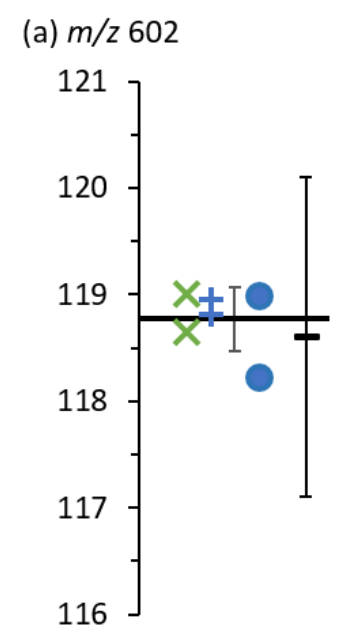

(b) $m / z 1034$

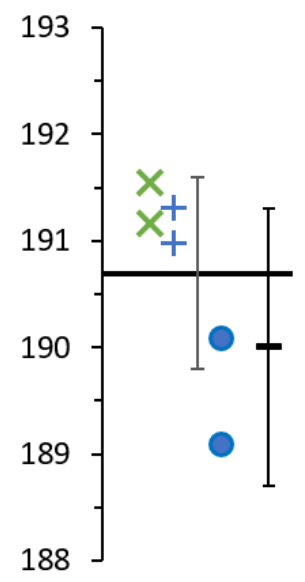

(d) $m / z 1634$

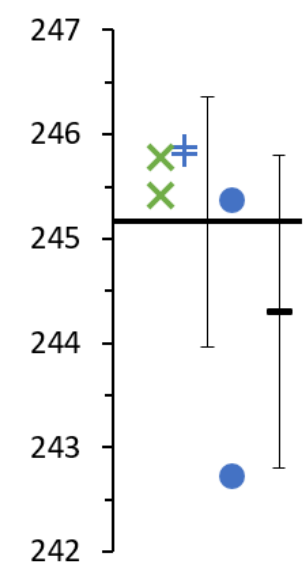

(e) $m / z 1934$

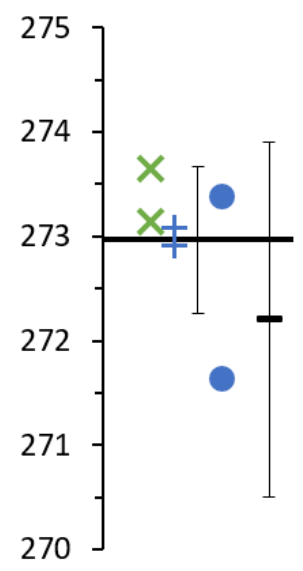

(c) $m / z 1334$

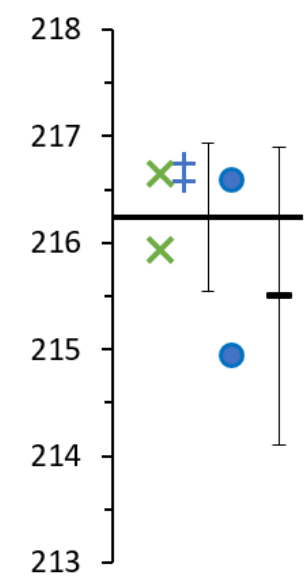

(f) $m / z 2234$

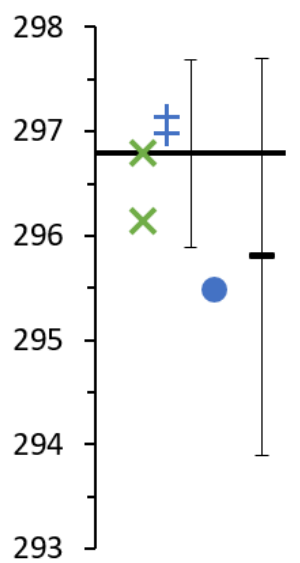

Figure 4. ${ }^{\mathrm{DT}} \mathrm{CCS} \mathrm{He}_{\mathrm{He}}$ values $\left(\AA^{2}\right)$ at $296.6 \mathrm{~K}$ for tuning mix anions $\mathrm{m} / \mathrm{z} 602(\mathrm{a}), 1034$ (b), 1334 (c), 1634 (d), 1934 (e), and 2234 (f). Green diagonal crosses are ${ }^{\text {DT }}$ CCS $_{\mathrm{He}}$ values determined from soft pre-IMS parameters and harsh pre-IMS parameters from tuning mix solutions. Blue crosses are ${ }^{\mathrm{DT}} \mathrm{CCS}_{\mathrm{He}}$ values determined from harsh pre-IMS parameters and harsh pre-IMS parameters from an Agilent tuning mix solution in mixture with phosphoric acid. Blue circles are ${ }^{\mathrm{DT}} \mathrm{CCS}_{\mathrm{He}}$ values determined from harsh pre- and post-IMS parameters from a pure Agilent tuning mix solution. The mean experimental value is represented as a thick black horizontal line with error bars representing the standard deviation $\sigma$. The Anal Chem 2017 [36] values at $296 \mathrm{~K}$ with their standard deviations $\sigma$ are represented on the right with a dark horizontal mark. 
We then evaluated if a change of the peak profiles and a variable proportion of dissociation affected the CCS values of phosphoric acid cluster anions. We used overlaid EIM spectra to perform careful peak assignment for the experiments carried out with harsh post-IMS conditions. We determined the CCS values of phosphoric acid cluster anions with charge state between 1-and 4-for which the attribution was unambiguous. Each CCS was determined from the slope of the linear correlation obtained with all five electric field values. The ${ }^{\mathrm{DT}} \mathrm{CCS}_{\mathrm{He}}$ values and the standard deviation $(\sigma)$ of replicated experiments $(n=10)$ for a subset of singly, doubly, triply and quadruply charged phosphoric acid clusters are shown in Figure 5 (and Table S4). We obtained very consistent CCS values for phosphoric acid cluster anions in all explored experimental conditions also in presence of high extents of fragmentation. We hence treated all experimental conditions as repeated measurements and determined the ${ }^{\mathrm{DT}} \mathrm{CCS}_{\mathrm{He}}$ values for 75 phosphoric acid cluster anions with charge state up to 4- by averaging CCS from at least three different experiments at different experimental conditions (Table 1).

Table 1 gathers the mean reduced ion mobilities $K_{0}$, the mean ${ }^{\mathrm{DT}} \mathrm{CCS}_{\mathrm{He}}$ and the type $\mathrm{A}$ experimental standard deviations $(\sigma)$ obtained from three to ten replicates $(n)$. The difference in the number of replicates $n$ comes from the fact that some signals were not visible in every experiment, because the different voltage parameters applied in the pre-IMS and post-IMS areas led to differences in the relative proportion of the charge states and in the amount of dissociation. Only the cluster anions with reliable signal attribution were retained. We obtained a maximum relative standard deviation of $1.7 \%$, and on average the RSD was $0.4 \%$.

We also performed a type B evaluation of the uncertainty on a ${ }^{\mathrm{DT}} \mathrm{CCS}_{\mathrm{He}}$ value applying the propagation of errors on the result of the Mason-Schamp equation. Taking into account the stochastic nature of the Monte Carlo method and the impossibility to reach a direct control on the degree of freedom by simply choosing a priori the number of trials $\left(n_{T}\right)$, we set the program to select $n_{T}$ adaptively as the simulation proceeds in order to reach a $95 \%$ coverage interval, as suggested by Cox et al. [38]. The simulation stopped at $n_{T} \sim 6 \times 10^{6}$ and the normal distribution obtained for the ${ }^{\text {DT }} \mathrm{CCS}_{\mathrm{He}}$ of the $\mathrm{P} \# 8^{-}$cluster anion of $150.9 \AA^{2}$ yielded a standard deviation (equivalent to a combined uncertainty $u_{c}$ ) of $\sim 3.0 \AA^{2}$ which amounts to a relative combined standard uncertainty of $\sim 2.0 \%$. It makes sense that this value is slightly higher than the relative standard deviations observed from our replicate measurements (0.6 to $1.7 \%$ RSD), because it takes into account more contributions to uncertainty.

The collected values of ${ }^{\mathrm{DT}} \mathrm{CCS}_{\mathrm{He}}$ of phosphoric acid cluster anions could be fitted to the power function $41.1 n^{0.61}$ where $n$ is the aggregation number. The determination coefficient $R^{2}$ of this fit obtained from seventy-five ${ }^{\mathrm{DT}} \mathrm{CCS}_{\mathrm{He}}$ values of cluster anions with aggregation numbers from 4 to 89 was 0.9992 (Figure 6). This power function growth was also observed for the ${ }^{\mathrm{DT}} \mathrm{CCS}\left(\mathrm{N}_{2}\right)$ values determined before for which the function was $79.6 n^{0.51}$ [25]. Only sixteen clusters were common to the two studies, among the singly, doubly and triply charged cluster anions. The ${ }^{\mathrm{DT}} \mathrm{CCS}_{\mathrm{He}}$ values determined here and the ${ }^{\mathrm{DT}} \mathrm{CCS}_{\mathrm{N}_{2}}$ determined previously on the TOFWerk instrument showed an excellent linear correlation (Figure S5). 
(a) $\mathrm{P \# 8^{- }} \mathrm{m} / \mathrm{z} 782.8$

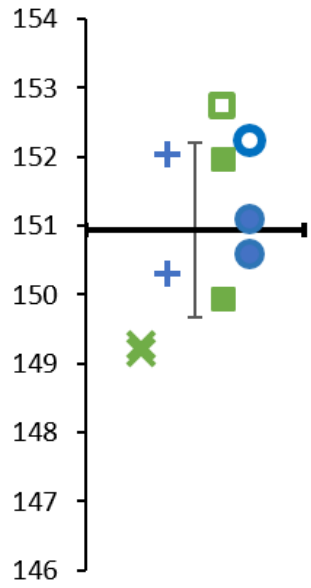

(e) P\#42 $3 / \mathrm{m} 1370.6$

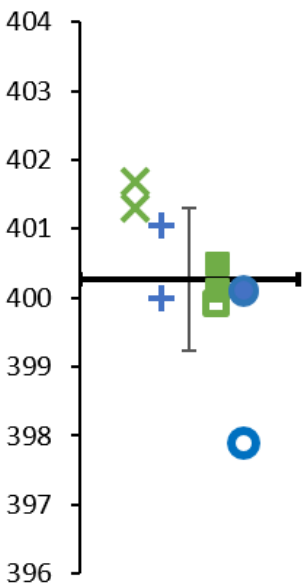

(b) P\#10- $\mathrm{m} / \mathrm{z} 978.8$

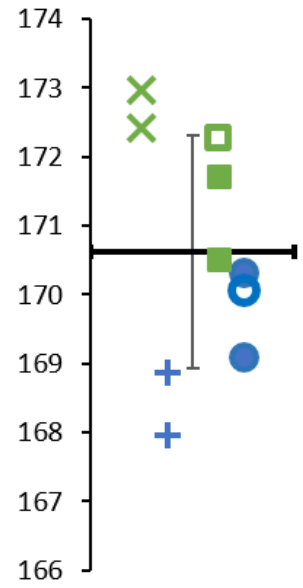

(f) $P \# 52^{3-} \mathrm{m} / \mathrm{z} 1397.3$

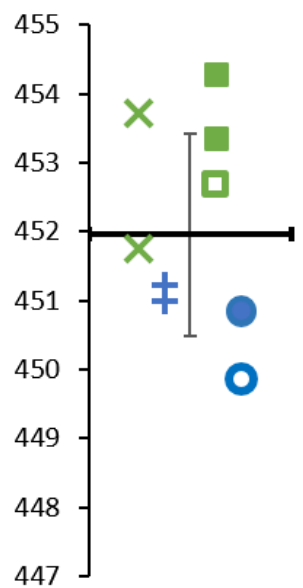

(c) P\#202- $\mathrm{m} / \mathrm{z} 978.8$

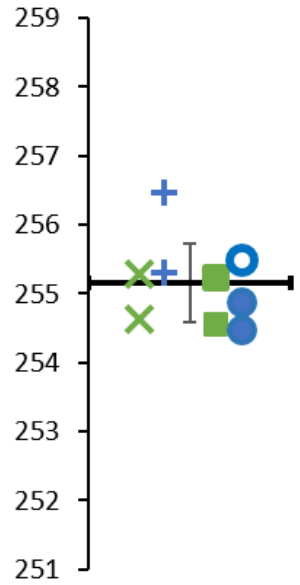

(g) P\#674- $\mathrm{m} / \mathrm{z} 1640.1$

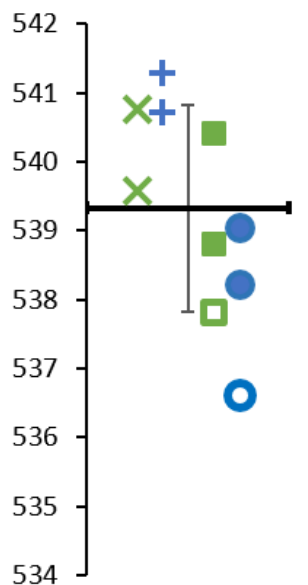

(d) P\#252- $\mathrm{m} / \mathrm{z} 1223.7$

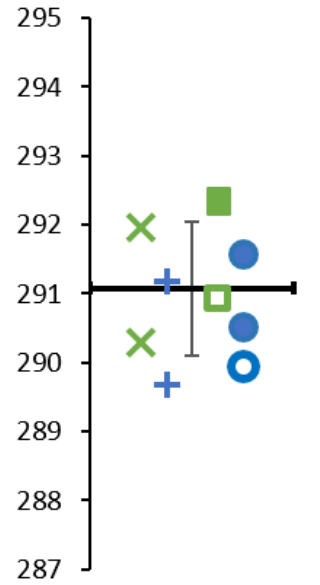

(h) P\#704- $\mathrm{m} / \mathrm{z} 1713 . \epsilon$

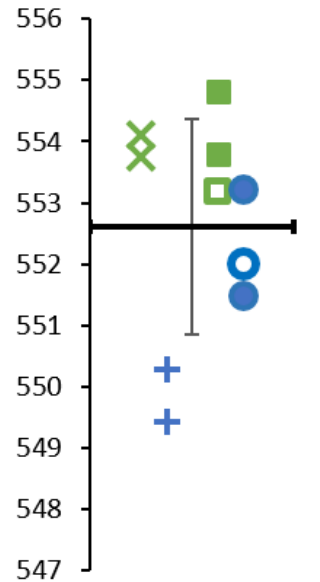

Figure 5. ${ }^{\text {DT }} \mathrm{CCS}_{\mathrm{He}}$ values $\left(\AA^{2}\right)$ at $296.6 \mathrm{~K}$ for eight sample $\mathrm{H}_{3} \mathrm{PO}_{4}$ cluster anions with charge state

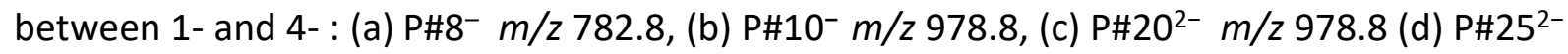

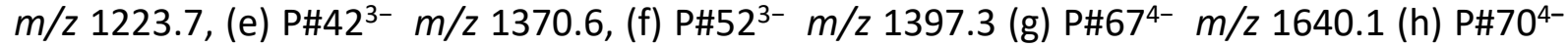
$m / z$ 1713.6. Green: ${ }^{\mathrm{DT}} \mathrm{CCS}_{\mathrm{He}}$ values determined using soft pre-IMS tuning. Blue: ${ }^{\mathrm{DT}} \mathrm{CCS}_{\mathrm{He}}$ values determined using harsh pre-IMS. Open symbols (green squares and blue circles): ${ }^{\mathrm{DT}} \mathrm{CCS}_{\mathrm{He}}$ values determined from experiments with a soft post-IMS gradient. All other ${ }^{\mathrm{DT} C C \mathrm{~S}_{\mathrm{He}} \text { values }}$ were determined from harsh post-IMS conditions. Green diagonal crosses and blue crosses: ${ }^{\mathrm{DT}} \mathrm{CCS}_{\mathrm{He}}$ values obtained from a mixture of phosphoric acid and tuning mix. All other ${ }^{\mathrm{DT}} \mathrm{CCS}_{\mathrm{He}}$ values were obtained from a pure phosphoric acid solution. The mean experimental value is represented as a thick black horizontal line with error bars representing the standard deviation $\sigma(n=10)$.

Similar power function growth has been observed before for proteins [39] and, Bleiholder et al. [40] reasoned that isotropic growth of the collision cross-section $\Omega$ should be related to the oligomeric state $n$ by equation 4:

$$
\Omega=\mathrm{A} n^{2 / 3}
$$

where $A$ is the monomer collision cross section. The power function observed for phosphoric acid cluster anions was 0.51 in nitrogen [25] and 0.61 in helium (this work). 
De Pauw and co-workers $[41,42]$ have also observed such power function growth trends for polymer-cation complexes of different charge states (poly(ethoxyphosphate), poly(ethyleneoxide) and poly(caprolactone)) and oligorotaxane foldamers, with exponent values ranging from 0.50 to 0.93 . They interpret the constant $A$ as an apparent charge density or charge solvation capacity of the monomer unit. For polymers, the $A$ value depends on the chemical nature of the monomer, but also on the charge state. Several multiply charged polymers were observed to transition from one power function fit to another depending on the degree of polymerization, reflecting a structural rearrangement. Here, the A value was the same whatever the charge state, which thus indicated a constant charge solvation capacity of phosphoric acid. Also, there was virtually no overlap with several charge states for a given aggregation number. We thus conclude that, for a given charge state when the aggregation number decreased and the charge density was too high, the clusters dissociated, and the smaller clusters should have a similar shape as the larger ones. We hypothesize that the cluster ions are roughly spherical, similarly to a nanodroplet of liquid phosphoric acid.

The fact that the exponential factors differed in helium and nitrogen gas could indicate that interactions with the drift gas also plays a role in the CCS values and trends. The exponent in helium is the closest to $2 / 3$, but not equal. The interpretation of both $A$ and exponential factor values should therefore not only focus on the geometry or charge solvation capacity of the analyte ions, but also on its interaction with the drift gas. Our study illustrates another interest of recording CCS trends in helium and compare them with nitrogen values on the same analytes, having defined shapes and apparent densities [43].

In figure $6 \mathrm{~b}$, the comparison of the ${ }^{\mathrm{DT}} \mathrm{CCS}_{\mathrm{He}}$ values of phosphoric acid cluster anions with that of the tuning mix ions [36] highlights that both sets cover a similar range of $m / z$ but the phosphoric acid cluster anions cover a broader range of charge states and CCS. Covering several charge states is an advantage as it is currently deemed safer to match the charge state of the analyte and the calibrant $[16,25]$. The different charge states follow different mobility$m / z$ trends (Figure $6 \mathrm{c}$ ).

In TWIMS, it is also recommended to match molecular classes [44]. This latter recommendation is not always complied with and would require further investigation. In fact, the polymer poly-(ethylene oxide) monomethyl ether (PEO) have been shown to be good calibrants for peptides, in the positive ion mode, for tryptic peptides of BSA [45]. One condition to obtain a reliable calibration is to ascertain that the ion mobilities of the ions are comparable in different ion mobility setups, which was shown for PEO polymers [46].

A comparison of the reduced mobilities (Figure $6 \mathrm{c}$ ) shows that the singly charged tuning mix ions alone cover a wide interval ranging from 1.82 to $4.55 \mathrm{~cm}^{2} \mathrm{~V}^{-1} \mathrm{~s}^{-1}$ and that, except for the reduced mobility of the $\mathrm{P \#}^{-}$(at $5.65 \mathrm{~cm}^{2} \mathrm{~V}^{-1} \mathrm{~s}^{-1}$ ), the differently charged phosphoric acid cluster ions fall collectively in an analogous range between 2.74 and $4.36 \mathrm{~cm}^{2} \mathrm{~V}^{-1} \mathrm{~s}^{-1}$. Reduced ion mobilities $K_{0}$ are more often used for calibration of trapped ion mobility devices (TIMS) [47, 48]. Here, the advantage of phosphoric acid cluster anions would be to provide many values in a given ion mobility range. 
(a)

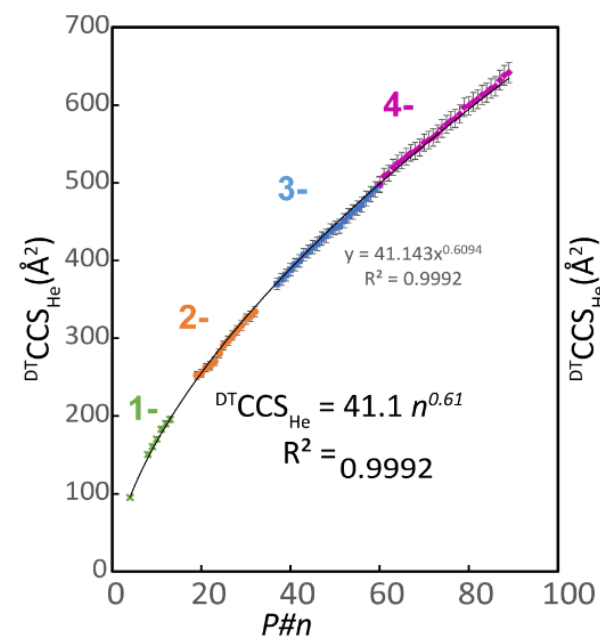

(b)

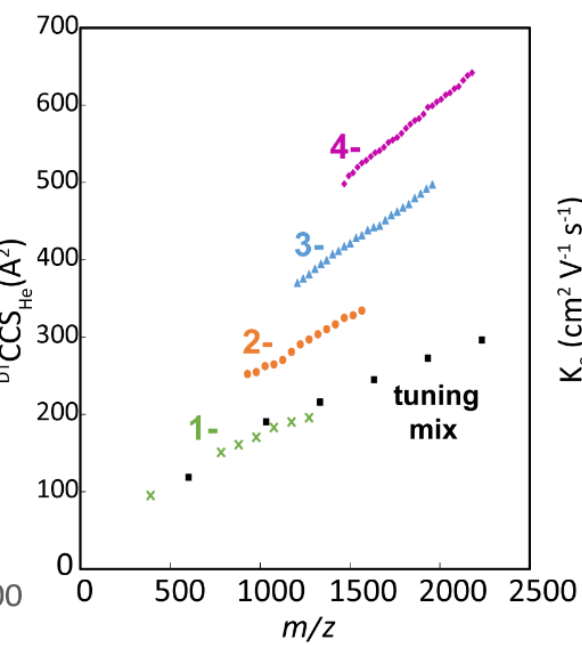

(c)

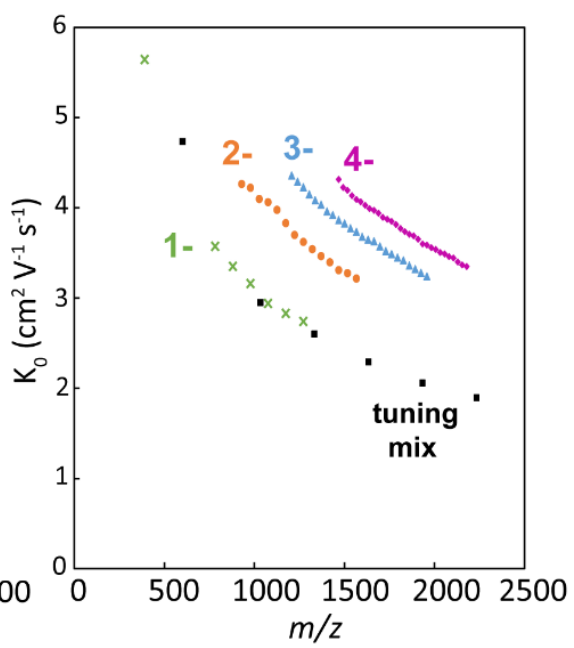

Figure 6. a) ${ }^{{ }^{\top} T} \mathrm{CCS}_{\mathrm{He}}$ of phosphoric acid cluster anions vs their aggregation number $n$ b) ${ }^{{ }^{\mathrm{T}} \mathrm{CCS}_{\mathrm{He}}}$ vs $m / z$ c) reduced ion mobilities $K_{0}$ vs $m / z$ for phosphoric acid cluster anions and tuning mix ions. The different charge states for $\mathrm{H}_{3} \mathrm{PO}_{4}$ cluster anions are shown by green crosses $(z=1-)$, orange circles $(z=2-)$, blue triangles $(z=3-)$ and magenta diamonds $(z=4-)$. Singly charged tuning mix anions ( $\mathrm{m} / \mathrm{z} 602$ to 1934$)$ are represented by black full squares. Error bars in panel (a) represent the $2 \%$ relative standard uncertainty. Error bars with the observed relative standard deviation from all replicates would have nearly the same size as the symbols. 
Table 1. ${ }^{\mathrm{DT}} \mathrm{CCS}_{\mathrm{He}}\left(\AA^{2}\right)$ and $K_{0}\left(\mathrm{~cm}^{2} \mathrm{~V}^{-1} \mathrm{~s}^{-1}\right)$ for phosphoric acid cluster anions with charge state up to $4-$ with type $A$ statistical analysis $\left(\sigma_{K_{0}}\right.$ is the standard deviation of the reduced mobilities, $u$ is the experimental standard deviation of the mean (calculated as $\sigma / \sqrt{n}$ ), $\sigma$ is the standard deviation on ${ }^{\mathrm{DT}} \mathrm{CCS}_{\mathrm{He}}$ and $n$ is the number of replicates).

\begin{tabular}{|c|c|c|c|c|c|c|c|c|c|c|c|c|c|c|c|c|c|c|c|}
\hline \multirow{2}{*}{$\begin{array}{l}z \\
1-\end{array}$} & \multirow{2}{*}{$\frac{m / z}{390.9}$} & \multirow{2}{*}{$\frac{\text { P\# }}{}$} & \multirow{2}{*}{$\begin{array}{c}K_{0} \\
\left(\mathbf{c m}^{2}\right. \\
\mathbf{V}^{-1} \mathbf{s}^{-} \\
\left.{ }^{1}\right) \\
5.671\end{array}$} & \multirow{2}{*}{$\begin{array}{c}\sigma_{\mathrm{K}_{0}} \\
(\mathbf{c m} 2 \\
\begin{array}{c}\mathrm{V}-1 \mathrm{~s}- \\
1)\end{array} \\
0.096\end{array}$} & \multicolumn{2}{|c|}{$\begin{array}{c}\mathrm{CCS} \pm \mathrm{u} \\
\left(\AA^{2}\right)\end{array}$} & \multirow{2}{*}{$\begin{array}{l}\sigma \\
\frac{\left(\AA^{2}\right)}{1.6}\end{array}$} & \multirow{2}{*}{$\begin{array}{c}R S D \\
(\%) \\
1.7\end{array}$} & \multirow{2}{*}{$\begin{array}{c}n \\
10\end{array}$} & \multirow[b]{2}{*}{ 3- } & \multirow{2}{*}{$\begin{array}{c}m / z \\
1729.9\end{array}$} & \multirow{2}{*}{$\frac{\text { P\# }}{53}$} & \multirow{2}{*}{$\begin{array}{c}K_{0} \\
\left(\mathrm{~cm}^{2}\right. \\
\left.\mathbf{V}^{-1} \mathbf{s}^{-1}\right)\end{array}$} & \multirow{2}{*}{$\begin{array}{c}\sigma_{\mathrm{K}_{0}} \\
\left(\mathrm{~cm}^{2}\right. \\
\mathrm{V}^{-1} \mathrm{~s}^{-} \\
\left.{ }^{1}\right) \\
0.008\end{array}$} & \multicolumn{2}{|c|}{$\begin{array}{c}\mathrm{CCS} \pm \mathrm{u} \\
\left(\AA^{2}\right)\end{array}$} & \multirow{2}{*}{$\begin{array}{c}\sigma \\
\left(\AA^{2}\right) \\
1.1\end{array}$} & \multirow{2}{*}{$\begin{array}{r}R S D \\
(\%) \\
0.24\end{array}$} & \multirow{2}{*}{$\begin{array}{l}n \\
10\end{array}$} \\
\hline & & & & & 95.2 & \pm 0.6 & & & & & & & & & 458.5 & \pm 0.4 & & & \\
\hline 1- & 782.9 & 8 & 3.568 & 0.03 & 150.9 & \pm 0.5 & 1.3 & 0.86 & 10 & 3- & 1762.6 & 54 & 3.482 & 0.014 & 463.0 & \pm 0.6 & 1.8 & 0.39 & 8 \\
\hline 1- & 880.8 & 9 & 3.346 & 0.044 & 161.0 & \pm 0.7 & 2.1 & 1.3 & 10 & 3- & 1795.2 & 55 & 3.443 & 0.006 & 468.2 & \pm 0.3 & 0.8 & 0.17 & 8 \\
\hline 1- & 978.8 & 10 & 3.155 & 0.031 & 170.6 & \pm 0.6 & 1.7 & 1.0 & 10 & 3- & 1827.9 & 56 & 3.412 & 0.007 & 472.5 & \pm 0.3 & 1.0 & 0.21 & 8 \\
\hline 1- & 1076.7 & 11 & 2.935 & 0.013 & 183.4 & \pm 0.3 & 0.8 & 0.44 & 10 & 3- & 1860.5 & 57 & 3.355 & 0.007 & 480.5 & \pm 0.4 & 1.0 & 0.21 & 8 \\
\hline 1- & 1174.7 & 12 & 2.825 & 0.025 & 190.5 & \pm 0.6 & 1.7 & 0.89 & 10 & 3- & 1893.2 & 58 & 3.316 & 0.006 & 486.2 & \pm 0.3 & 0.9 & 0.19 & 7 \\
\hline \multirow[t]{2}{*}{ 1- } & 1272.7 & 13 & 2.736 & 0.044 & 196.0 & \pm 0.9 & 2.6 & 1.3 & 8 & 3- & 1925.8 & 59 & 3.275 & 0.016 & 492.3 & \pm 0.8 & 2.4 & 0.49 & 3 \\
\hline & & & & & & & & & & 3- & 1958.5 & 60 & 3.237 & 0.005 & 498.1 & \pm 0.3 & 0.8 & 0.16 & 3 \\
\hline $2-$ & 929.8 & 19 & 4.257 & 0.024 & 252.7 & \pm 0.5 & 1.4 & 0.56 & 10 & & & & & & & & & & \\
\hline $2-$ & 978.8 & 20 & 4.215 & 0.01 & 255.2 & \pm 0.2 & 0.6 & 0.24 & 10 & 4- & 1468.6 & 60 & 4.308 & 0.018 & 498.9 & \pm 0.7 & 2.1 & 0.42 & 8 \\
\hline $2-$ & 1027.8 & 21 & 4.092 & 0.03 & 262.8 & \pm 0.7 & 1.9 & 0.72 & 10 & 4- & 1493.1 & 61 & 4.220 & 0.008 & 509.4 & \pm 0.3 & 0.9 & 0.18 & 8 \\
\hline $2-$ & 1076.7 & 22 & 4.057 & 0.011 & 265.1 & \pm 0.3 & 0.7 & 0.26 & 10 & 4- & 1517.6 & 62 & 4.189 & 0.009 & 513.2 & \pm 0.4 & 1.1 & 0.21 & 8 \\
\hline $2-$ & 1125.7 & 23 & 3.971 & 0.023 & 270.8 & \pm 0.5 & 1.5 & 0.55 & 10 & 4- & 1542.1 & 63 & 4.129 & 0.009 & 520.6 & \pm 0.4 & 1.1 & 0.21 & 8 \\
\hline $2-$ & 1174.7 & 24 & 3.824 & 0.014 & 281.2 & \pm 0.3 & 1.0 & 0.36 & 10 & 4- & 1566.6 & 64 & 4.087 & 0.019 & 525.9 & \pm 0.8 & 2.4 & 0.46 & 8 \\
\hline $2-$ & 1223.7 & 25 & 3.694 & 0.012 & 291.1 & \pm 0.3 & 1.0 & 0.34 & 10 & 4- & 1591.1 & 65 & 4.060 & 0.014 & 529.4 & \pm 0.6 & 1.9 & 0.36 & 8 \\
\hline $2-$ & 1272.7 & 26 & 3.616 & 0.011 & 297.4 & \pm 0.3 & 0.9 & 0.30 & 10 & 4- & 1615.6 & 66 & 4.022 & 0.015 & 534.4 & \pm 0.7 & 2.0 & 0.37 & 8 \\
\hline $2-$ & 1321.7 & 27 & 3.537 & 0.014 & 304.0 & \pm 0.4 & 1.2 & 0.40 & 10 & 4- & 1640.1 & 67 & 3.986 & 0.011 & 539.3 & \pm 0.5 & 1.5 & 0.28 & 10 \\
\hline $2-$ & 1370.7 & 28 & 3.460 & 0.013 & 310.8 & \pm 0.4 & 1.1 & 0.35 & 10 & 4- & 1664.6 & 68 & 3.967 & 0.02 & 541.9 & \pm 0.9 & 2.7 & 0.50 & 10 \\
\hline $2-$ & 1419.6 & 29 & 3.392 & 0.009 & 316.9 & \pm 0.3 & 0.8 & 0.25 & 10 & 4- & 1689.1 & 69 & 3.934 & 0.011 & 546.4 & \pm 0.5 & 1.5 & 0.27 & 10 \\
\hline $2-$ & 1468.6 & 30 & 3.305 & 0.009 & 325.3 & \pm 0.3 & 0.9 & 0.28 & 6 & 4- & 1713.6 & 70 & 3.890 & 0.012 & 552.6 & \pm 0.6 & 1.8 & 0.33 & 10 \\
\hline $2-$ & 1517.6 & 31 & 3.271 & 0.008 & 328.7 & \pm 0.3 & 0.8 & 0.24 & 5 & 4- & 1738.1 & 71 & 3.867 & 0.014 & 555.8 & \pm 0.7 & 2.0 & 0.36 & 10 \\
\hline $2-$ & 1566.6 & 32 & 3.211 & 0.005 & 334.8 & \pm 0.3 & 0.5 & 0.15 & 5 & 4- & 1762.6 & 72 & 3.844 & 0.019 & 559.1 & \pm 0.9 & 2.8 & 0.50 & 10 \\
\hline & & & & & & & & & & 4- & 1787.1 & 73 & 3.809 & 0.012 & 564.3 & \pm 0.6 & 1.7 & 0.30 & 10 \\
\hline 3- & 1207.4 & 37 & 4.351 & 0.017 & 370.6 & \pm 0.5 & 1.5 & 0.41 & 8 & 4- & 1811.6 & 74 & 3.765 & 0.018 & 570.9 & \pm 0.9 & 2.7 & 0.47 & 10 \\
\hline 3- & 1240 & 38 & 4.284 & 0.01 & 376.4 & \pm 0.3 & 0.9 & 0.24 & 10 & 4- & 1836 & 75 & 3.731 & 0.014 & 576.2 & \pm 0.7 & 2.1 & 0.37 & 8 \\
\hline 3- & 1272.7 & 39 & 4.207 & 0.048 & 383.3 & \pm 1.5 & 4.5 & 1.2 & 10 & 4- & 1860.5 & 76 & 3.700 & 0.014 & 580.9 & \pm 0.7 & 2.2 & 0.38 & 8 \\
\hline 3- & 1305.3 & 40 & 4.145 & 0.012 & 389.0 & \pm 0.4 & 1.1 & 0.28 & 10 & 4- & 1885 & 77 & 3.682 & 0.012 & 583.7 & \pm 0.6 & 1.9 & 0.33 & 8 \\
\hline 3- & 1338 & 41 & 4.079 & 0.012 & 395.3 & \pm 0.4 & 1.2 & 0.30 & 10 & 4- & 1909.5 & 78 & 3.647 & 0.014 & 589.3 & \pm 0.7 & 2.2 & 0.37 & 8 \\
\hline 3- & 1370.7 & 42 & 4.028 & 0.01 & 400.3 & \pm 0.3 & 1.0 & 0.25 & 10 & 4- & 1934 & 79 & 3.594 & 0.007 & 598.1 & \pm 0.4 & 1.2 & 0.2 & 8 \\
\hline 3- & 1403.3 & 43 & 3.954 & 0.005 & 407.8 & \pm 0.2 & 0.6 & 0.15 & 10 & 4- & 1958.5 & 80 & 3.582 & 0.016 & 600.1 & \pm 0.9 & 2.6 & 0.43 & 8 \\
\hline 3- & 1435.9 & 44 & 3.913 & 0.007 & 412.1 & \pm 0.2 & 0.7 & 0.17 & 10 & 4- & 1983 & 81 & 3.552 & 0.013 & 605.1 & \pm 0.7 & 2.2 & 0.36 & 8 \\
\hline 3- & 1468.6 & 45 & 3.858 & 0.009 & 417.9 & \pm 0.3 & 1.0 & 0.24 & 10 & 4- & 2007.5 & 82 & 3.533 & 0.015 & 608.5 & \pm 0.9 & 2.6 & 0.43 & 8 \\
\hline 3- & 1501.3 & 46 & 3.820 & 0.005 & 422.0 & \pm 0.2 & 0.6 & 0.14 & 10 & 4- & 2032 & 83 & 3.500 & 0.007 & 614.0 & \pm 0.4 & 1.2 & 0.20 & 8 \\
\hline 3- & 1533.9 & 47 & 3.767 & 0.005 & 429.0 & \pm 0.6 & 1.8 & 0.42 & 10 & 4- & 2056.5 & 84 & 3.483 & 0.01 & 617.0 & \pm 0.6 & 1.8 & 0.29 & 8 \\
\hline 3- & 1566.6 & 48 & 3.728 & 0.005 & 432.5 & \pm 0.2 & 0.5 & 0.12 & 10 & 4- & 2081 & 85 & 3.454 & 0.009 & 622.2 & \pm 0.6 & 1.7 & 0.27 & 6 \\
\hline 3- & 1599.3 & 49 & 3.673 & 0.01 & 439.0 & \pm 0.4 & 1.2 & 0.27 & 10 & 4- & 2105.5 & 86 & 3.438 & 0.006 & 625.1 & \pm 0.4 & 1.1 & 0.18 & 6 \\
\hline 3- & 1631.9 & 50 & 3.642 & 0.008 & 442.7 & \pm 0.3 & 0.9 & 0.2 & 10 & 4- & 2130 & 87 & 3.395 & 0.006 & 633.1 & \pm 0.4 & 1.0 & 0.16 & 6 \\
\hline 3- & 1664.6 & 51 & 3.625 & 0.009 & 444.8 & \pm 0.4 & 1.1 & 0.25 & 10 & 4- & 2154.5 & 88 & 3.362 & 0.01 & 639.3 & \pm 0.7 & 2.0 & 0.31 & 6 \\
\hline 3- & 1697.2 & 52 & 3.567 & 0.012 & 452.0 & \pm 0.5 & 1.5 & 0.33 & 10 & 4- & 2178.9 & 89 & 3.344 & 0.007 & 642.8 & \pm 0.5 & 1.3 & 0.20 & 6 \\
\hline
\end{tabular}




\section{Conclusions}

Phosphoric acid is a very affordable compound that forms cluster ions by direct infusion of its solution into an electrospray ionization source. In the present paper, we assessed the influence of activating parameters before and after the ion mobility cell, on their ${ }^{\mathrm{DT}} \mathrm{CCS}_{\mathrm{He}}$ values. Different experimental conditions operated in the area before the ion mobility device expectedly produced different proportions of singly and multiply charged species, while different post-IMS conditions affected the profile of the extracted ion mobility spectra and the ion mobility peak signals. Indeed, dissociation of the phosphoric cluster anions which correspond to cleavage of hydrogen bonds after the ion mobility device could be observed for cluster ions with low charge states and aggregation number $n$.

After a careful identification of the peaks corresponding to the intact clusters, we observed that ${ }^{\mathrm{DT} C C S} \mathrm{H}_{\mathrm{H}}$ values determined by classic multi-field measurements did not vary with pre-IMS or post-IMS experimental conditions. The relative standard deviation of ${ }^{\mathrm{DT}} \mathrm{CCS}_{\mathrm{He}}$ from three to ten replicates was less than $1.7 \%$. The propagation of the errors on ${ }^{\mathrm{DT}} \mathrm{CCS}_{\mathrm{He}}$ from the physical and instrumental parameters led to a relative combined uncertainty of $2 \%$.

This collection of seventy-five ${ }^{\mathrm{DT}} \mathrm{CCS}_{\mathrm{He}}$ values for phosphoric cluster anions come as a first set of data for which the influence of different instrumental settings was assessed. This extensive set of values which range four different charges states for negative ions (1- to 4-) and ${ }^{\mathrm{DT}} \mathrm{CCS}_{\mathrm{He}}$ values from 95.1 to $641.7 \AA^{2}$ ( $K_{0}$ values from 5.861 to $2.741 \mathrm{~cm}^{2} \mathrm{~V}^{-1} \mathrm{~s}^{-1}$ ), are all associated with one single and very accessible compound. As they are regularly spaced and close in value, these ${ }^{\mathrm{DT}} \mathrm{CCS}_{\mathrm{He}}$ values could be used in the calibration of non-uniform electric field drift cells. Using these values for calibration of TWIMS and TIMS will be the object of future work.

\section{Electronic supplementary information}

Detailed experimental conditions and related voltages used on the Agilent 6560 IMS-QTOF and Synapt G2 instruments; linear regression and evaluation on uncertainty for slope and intercept; full mass spectra of singly and multiply phosphoric acid cluster ions, ammonia and sodium adducts; CID spectrum obtained by ion mobility tandem mass spectrometry for a sample triply charged ammonia adduct; experimental ${ }^{D T} \mathrm{CCS}_{\mathrm{He}}$ values $\left(\AA^{2}\right)$ of tuning mix and sample $\mathrm{H}_{3} \mathrm{PO}_{4}$ cluster anions; correlation between the ${ }^{\mathrm{DT}} \mathrm{CCS}(\mathrm{He})$ with ${ }^{\mathrm{DT}} \mathrm{CCS}\left(\mathrm{N}_{2}\right)$ values.

\section{Acknowledgements}

This work was financed by Région Normandie (GREENCHEM), the Labex SynOrg (ANR-11LABX-0029) and the European Regional Development Fund (ERDF HN0001343). The DTIMS experiments were performed at the Plateforme de BioPhysicoChimie Structurale at IECB.

\section{References}

1. Zeleny, J.: VI. On the ratio of the velocities of the two ions produced in gases by Röntgen radiation; and on some related phenomena. The London, Edinburgh, and Dublin Philosophical Magazine and Journal of Science. 46, 120-154 (1898)

2. Eiceman, G.A., Karpas, Z., Hill Jr, H.H. (Third edition ed.). CRC Press, (2013)

3. Gabelica, V., Marklund, E.: Fundamentals of ion mobility spectrometry. Curr Opin Chem Biol. 42, 51-59 (2018)

4. Kanu, A.B., Dwivedi, P., Tam, M., Matz, L., Hill, H.H., Jr.: Ion mobility-mass spectrometry. J Mass Spectrom. 43, 1-22 (2008) 
5. Campuzano, I.D., Lippens, J.L.: Ion mobility in the pharmaceutical industry: an established biophysical technique or still niche? Curr Opin Chem Biol. 42, 147-159 (2018)

6. Dwivedi, P., Schultz, A.J., Hill, H.H.: Metabolic Profiling of Human Blood by High Resolution Ion Mobility Mass Spectrometry (IM-MS). Int J Mass Spectrom. 298, 78-90 (2010)

7. McLean, J.A., Ruotolo, B.T., Gillig, K.J., Russell, D.H.: Ion mobility-mass spectrometry: a new paradigm for proteomics. Int J Mass Spectrom. 240, 301-315 (2005)

8. Ahmed, A., Cho, Y.J., No, M.H., Koh, J., Tomczyk, N., Giles, K., Yoo, J.S., Kim, S.: Application of the Mason-Schamp equation and ion mobility mass spectrometry to identify structurally related compounds in crude oil. Anal Chem. 83, 77-83 (2011)

9. May, J.C., McLean, J.A.: Ion mobility-mass spectrometry: time-dispersive instrumentation. Anal Chem. 87, 1422-1436 (2015)

10. Shvartsburg, A.A., Smith, R.D.: Fundamentals of traveling wave ion mobility spectrometry. Anal Chem. 80, 9689-9699 (2008)

11. Fernandez-Lima, F., Kaplan, D.A., Suetering, J., Park, M.A.: Gas-phase separation using a trapped ion mobility spectrometer. Int J Ion Mobil Spectrom. 14, 93-98 (2011)

12. Tao, L., McLean, J.R., McLean, J.A., Russell, D.H.: A collision cross-section database of singlycharged peptide ions. J Am Soc Mass Spectrom. 18, 1232-1238 (2007)

13. Duez, Q., Chirot, F., Lienard, R., Josse, T., Choi, C., Coulembier, O., Dugourd, P., Cornil, J., Gerbaux, P., De Winter, J.: Polymers for Traveling Wave Ion Mobility Spectrometry Calibration. J Am Soc Mass Spectrom. 28, 2483-2491 (2017)

14. Pagel, K., Harvey, D.J.: Ion mobility-mass spectrometry of complex carbohydrates: collision cross sections of sodiated N-linked glycans. Anal Chem. 85, 5138-5145 (2013)

15. Forsythe, J.G., Petrov, A.S., Walker, C.A., Allen, S.J., Pellissier, J.S., Bush, M.F., Hud, N.V., Fernandez, F.M.: Collision cross section calibrants for negative ion mode traveling wave ion mobility-mass spectrometry. Analyst. 140, 6853-6861 (2015)

16. Gelb, A.S., Jarratt, R.E., Huang, Y., Dodds, E.D.: A study of calibrant selection in measurement of carbohydrate and peptide ion-neutral collision cross sections by traveling wave ion mobility spectrometry. Anal Chem. 86, 11396-11402 (2014)

17. Richardson, K., Langridge, D., Giles, K.: Fundamentals of travelling wave ion mobility revisited: I. Smoothly moving waves. International Journal of Mass Spectrometry. 428, 71-80 (2018)

18. Haler, J.R.N., Morsa, D., Lecomte, P., Jérôme, C., Far, J., De Pauw, E.: Predicting lon MobilityMass Spectrometry trends of polymers using the concept of apparent densities. Methods. 144, 125-133 (2018)

19. Hopper, J.T., Oldham, N.J.: Collision induced unfolding of protein ions in the gas phase studied by ion mobility-mass spectrometry: the effect of ligand binding on conformational stability. $J$ Am Soc Mass Spectrom. 20, 1851-1858 (2009)

20. Campbell, M.T., Glish, G.L.: Fragmentation in the ion transfer optics after differential ion mobility spectrometry produces multiple artifact monomer peaks. Int J Mass Spectrom. 425, 47-54 (2018)

21. Lavanant, H., Tognetti, V., Afonso, C.: Traveling wave ion mobility mass spectrometry and ab initio calculations of phosphoric acid clusters. J Am Soc Mass Spectrom. 25, 572-580 (2014)

22. Zhou, S., Hamburger, M.: Formation of Sodium Cluster lons in Electrospray Mass Spectrometry. Rap Commun Mass Spectrom. 10, 797-800 (1996)

23. Zhang, D., Cooks, R.G.: Doubly charged cluster ions $[(\mathrm{NaCl}) \mathrm{m}(\mathrm{Na}) 2] 2+$ : magic numbers, dissociation, and structure. Int J Mass Spectrom. 195-196, 667-684 (2000)

24. Schroder, D.: lon clustering in electrospray mass spectrometry of brine and other electrolyte solutions. Phys Chem Chem Phys. 14, 6382-6390 (2012)

25. Lavanant, H., Groessl, M., Afonso, C.: Collision cross sections of negative cluster ions of phosphoric acid in $\mathrm{N} 2$ determined by drift tube ion mobility and their use in travelling wave ion mobility. Int J Mass Spectrom. 442, 14-22 (2019)

26. May, J.C., Goodwin, C.R., Lareau, N.M., Leaptrot, K.L., Morris, C.B., Kurulugama, R.T., Mordehai, A., Klein, C., Barry, W., Darland, E., Overney, G., Imatani, K., Stafford, G.C., Fjeldsted, 
J.C., McLean, J.A.: Conformational ordering of biomolecules in the gas phase: nitrogen collision cross sections measured on a prototype high resolution drift tube ion mobility-mass spectrometer. Anal Chem. 86, 2107-2116 (2014)

27. Stow, S.M., Causon, T.J., Zheng, X., Kurulugama, R.T., Mairinger, T., May, J.C., Rennie, E.E., Baker, E.S., Smith, R.D., McLean, J.A., Hann, S., Fjeldsted, J.C.: An Interlaboratory Evaluation of Drift Tube Ion Mobility-Mass Spectrometry Collision Cross Section Measurements. Anal Chem. 89, 9048-9055 (2017)

28. Gabelica, V., Livet, S., Rosu, F.: Optimizing Native Ion Mobility Q-TOF in Helium and Nitrogen for Very Fragile Noncovalent Structures. J Am Soc Mass Spectrom. 29, 2189-2198 (2018)

29. Breuker, K., Oh, H., Horn, D.M., Cerda, B.A., McLafferty, F.W.: Detailed unfolding and folding of gaseous ubiquitin ions characterized by electron capture dissociation. J Am Chem Soc. 124, 6407-6420 (2002)

30. Mason, E.A., Schamp, H.W.: Mobility of gaseous lons in weak electric fields. Annals of Physics. 4, 233-270 (1958)

31. GUM 1995 with minor corrections. Evaluation of measurement data. Guide to the expression of uncertainty in measurement: BIPM

https://www.bipm.org/utils/common/documents/jcgm/JCGM_100_2008_E.pdf

32. Larriba-Andaluz, C., Fernandez-Garcia, J., Ewing, M.A., Hogan, C.J., Jr., Clemmer, D.E.: Gas molecule scattering \& ion mobility measurements for organic macro-ions in He versus $\mathrm{N}_{2}$ environments. Phys Chem Chem Phys. 17, 15019-15029 (2015)

33. Rus, J., Moro, D., Sillero, J.A., Royuela, J., Casado, A., Estevez-Molinero, F., Fernández de la Mora, J.: IMS-MS studies based on coupling a differential mobility analyzer (DMA) to commercial API-MS systems. Int J Mass Spectrom. 298, 30-40 (2010)

34. Ouyang, H., Larriba-Andaluz, C., Oberreit, D.R., Hogan, C.J., Jr.: The collision cross sections of iodide salt cluster ions in air via differential mobility analysis-mass spectrometry. J Am Soc Mass Spectrom. 24, 1833-1847 (2013)

35. Hogan, C.J., Jr., Fernandez de la Mora, J.: Tandem ion mobility-mass spectrometry (IMS-MS) study of ion evaporation from ionic liquid-acetonitrile nanodrops. Phys Chem Chem Phys. 11, 8079-8090 (2009)

36. Marchand, A., Livet, S., Rosu, F., Gabelica, V.: Drift Tube Ion Mobility: How to Reconstruct Collision Cross Section Distributions from Arrival Time Distributions? Anal Chem. 89, 1267412681 (2017)

37. Morris, C.B., May, J.C., Leaptrot, K.L., McLean, J.A.: Evaluating Separation Selectivity and Collision Cross Section Measurement Reproducibility in Helium, Nitrogen, Argon, and Carbon Dioxide Drift Gases for Drift Tube Ion Mobility-Mass Spectrometry. J Am Soc Mass Spectrom. 30, 1059-1068 (2019)

38. Cox, M., Harris, P., Siebert, B.R.L.: Evaluation of Measurement Uncertainty Based on the Propagation of Distributions Using Monte Carlo Simulation. Measurement Techniques. 46, 824-833 (2003)

39. Ruotolo, B.T., Benesch, J.L.P., Sandercock, A.M., Hyung, S.-J., Robinson, C.V.: Ion mobility-mass spectrometry analysis of large protein complexes. Nature protocols. 3, 1139-1152 (2008)

40. Bleiholder, C., Dupuis, N.F., Wyttenbach, T., Bowers, M.T.: Ion mobility-mass spectrometry reveals a conformational conversion from random assembly to $\beta$-sheet in amyloid fibril formation. Nature chemistry. 3, 172-177 (2011)

41. Haler, J.R.N., Morsa, D., Lecomte, P., Jerome, C., Far, J., De Pauw, E.: Predicting Ion MobilityMass Spectrometry trends of polymers using the concept of apparent densities. Methods. 144, 125-133 (2018)

42. Hanozin, E., Morsa, D., De Pauw, E.: Two-Parameter Power Formalism for Structural Screening of Ion Mobility Trends: Applied Study on Artificial Molecular Switches. J Phys Chem A. 123, 8043-8052 (2019) 
43. Bleiholder, C., Johnson, N.R., Contreras, S., Wyttenbach, T., Bowers, M.T.: Molecular Structures and Ion Mobility Cross Sections: Analysis of the Effects of He and $\mathrm{N}_{2}$ Buffer Gas. Anal Chem. 87, 7196-7203 (2015)

44. Gabelica, V., Shvartsburg, A.A., Afonso, C., Barran, P., Benesch, J.L.P., Bleiholder, C., Bowers, M.T., Bilbao, A., Bush, M.F., Campbell, J.L., Campuzano, I.D.G., Causon, T., Clowers, B.H., Creaser, C.S., De Pauw, E., Far, J., Fernandez-Lima, F., Fjeldsted, J.C., Giles, K., Groessl, M., Hogan, C.J., Jr., Hann, S., Kim, H.I., Kurulugama, R.T., May, J.C., McLean, J.A., Pagel, K., Richardson, K., Ridgeway, M.E., Rosu, F., Sobott, F., Thalassinos, K., Valentine, S.J., Wyttenbach, T.: Recommendations for reporting ion mobility Mass Spectrometry measurements. Mass Spectrom Rev. 38, 291-320 (2019)

45. Haler, J.R.N., Kune, C., Massonnet, P., Comby-Zerbino, C., Jordens, J., Honing, M., Mengerink, Y., Far, J., De Pauw, E.: Comprehensive Ion Mobility Calibration: Poly(ethylene oxide) Polymer Calibrants and General Strategies. Anal Chem. 89, 12076-12086 (2017)

46. Haler, J.R.N., Massonnet, P., Chirot, F., Kune, C., Comby-Zerbino, C., Jordens, J., Honing, M., Mengerink, Y., Far, J., Dugourd, P., De Pauw, E.: Comparison of Different Ion Mobility Setups Using Poly (Ethylene Oxide) PEO Polymers: Drift Tube, TIMS, and T-Wave. J Am Soc Mass Spectrom. 29, 114-120 (2018)

47. Silveira, J.A., Ridgeway, M.E., Park, M.A.: High Resolution Trapped lon Mobility Spectrometery of Peptides. Anal. Chem. 86, 5624-5627 (2014)

48. Hernandez, D.R., DeBord, J.D., Ridgeway, M.E., Kaplan, D.A., Park, M.A., Fernandez-Lima, F.: Ion dynamics in a trapped ion mobility spectrometer. The Analyst. 139, 1913 (2014) 


\section{For Table of Contents Only}

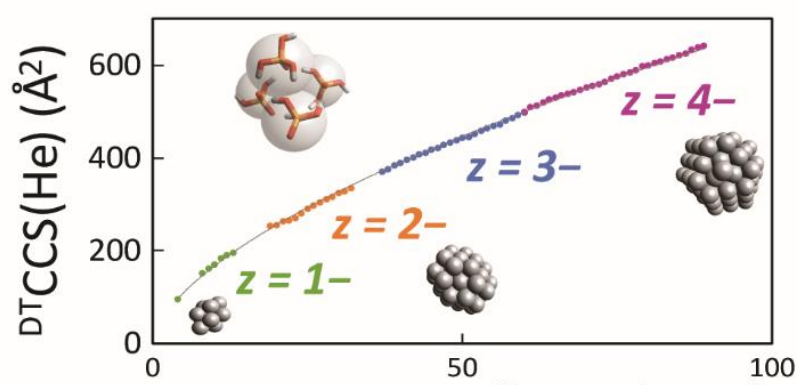

Aggregation number $\boldsymbol{n}$ in $\left[\left(\mathrm{H}_{3} \mathrm{PO}_{4}\right)_{n^{-}} \mathrm{zH}\right]^{z-}$ 


\section{Supporting Information}

Collision Cross Sections of Phosphoric Acid Cluster Anions in Helium Measured by Drift Tube Ion Mobility Mass Spectrometry

Valentina Calabrese ${ }^{1}$, Hélène Lavanant ${ }^{1 *}$, Frédéric Rosu ${ }^{2}$, Valérie Gabelica ${ }^{3}$, Carlos Afonso ${ }^{1}$

${ }^{1}$ Normandie Univ, UNIROUEN, INSA Rouen, CNRS, COBRA, 76000 Rouen, France

2 CNRS, University of Bordeaux and INSERM, Institut Européen de Chimie et Biologie (IECB, UMS3033, US001), 2 rue Robert Escarpit, 33600 Pessac, France

3 University of Bordeaux, INSERM and CNRS, Laboratoire Acides Nucléiques: Régulations Naturelle et Artificielle (ARNA, U1212, UMR5320), site IECB, 2 rue Robert Escarpit, 33600 Pessac, France

* Corresponding author:

Université de Rouen

IRCOF, 1 Rue Tesnière, 76821 Mont Saint Aignan Cedex, France.

Tel : +33235522932

helene.lavanant@univ-rouen.fr

\section{Electronic supplementary information}

Detailed experimental conditions and related voltages used on the Agilent 6560 IMS-QTOF and Synapt G2 instruments; linear regression and evaluation on uncertainty for slope and intercept; full mass spectra of singly and multiply phosphoric acid cluster ions, ammonia and sodium adducts; CID spectrum obtained by ion mobility tandem mass spectrometry for a sample triply charged ammonia adduct. 
Table S1 (a). List of the tuning parameters applied in the pre-IMS region

\begin{tabular}{|c|c|c|c|}
\hline \multicolumn{2}{|c|}{ Experimental conditions } & \multirow{2}{*}{$\begin{array}{c}\text { Soft or harsh PRE-IMS } \\
\text { Soft POST-IMS } \\
220^{\circ} \mathrm{C}\end{array}$} & \multirow{2}{*}{$\begin{array}{c}\begin{array}{c}\text { Soft or Harsh PRE-IMS } \\
\text { Harsh POST-IMS }\end{array} \\
220^{\circ} \mathrm{C}\end{array}$} \\
\hline \multirow{21}{*}{ 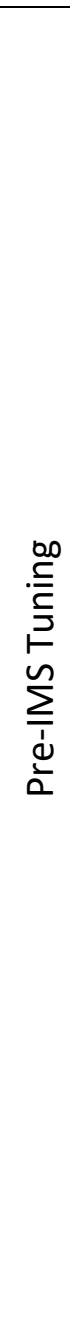 } & Source: gas temperature & & \\
\hline & Source: drying gas & $1.5 \mathrm{~L} / \mathrm{min}$ & $1.5 \mathrm{~L} / \mathrm{min}$ \\
\hline & Source: Nebulizer pressure & 9 psig & 9 psig \\
\hline & Source: capillary & $-3500 \mathrm{~V}$ & $-3500 \mathrm{~V}$ \\
\hline & Optics 1: FRAGMENTOR & $\begin{array}{l}\text { soft: }-300 \mathrm{~V} \\
\text { harsh: }-600 \mathrm{~V}\end{array}$ & $\begin{array}{l}\text { soft: }-300 \mathrm{~V} \\
\text { harsh: }-600 \mathrm{~V}\end{array}$ \\
\hline & $\begin{array}{l}\text { IM front funnel: high pressure } \\
\text { funnel delta }\end{array}$ & $-110 \mathrm{~V}$ & $-110 \mathrm{~V}$ \\
\hline & $\begin{array}{l}\text { IM front funnel: high pressure } \\
\text { funnel RF }\end{array}$ & $100-180 V_{p-p}$ & $100-180 V_{p-p}$ \\
\hline & IM front funnel: trap funnel delta & $-140 \mathrm{~V}$ & $-140 \mathrm{~V}$ \\
\hline & IM front funnel: trap funnel RF & $160 V_{p-p}$ & $160 V_{p-p}$ \\
\hline & IM front funnel: trap funnel exit & $-10 \mathrm{~V}$ & $-10 \mathrm{~V}$ \\
\hline & IM trap: trap entrance grid low & $-70 \mathrm{~V}$ & $-70 \mathrm{~V}$ \\
\hline & IM trap: trap entrance grid delta & $-2 \mathrm{~V}$ & $-2 \mathrm{~V}$ \\
\hline & IM trap: trap entrance & $-69 V$ & $-69 V$ \\
\hline & IM trap: trap exit & $-67 V$ & $-67 V$ \\
\hline & IM trap: trap exit grid 1 low & $-64 \mathrm{~V}$ & $-64 \mathrm{~V}$ \\
\hline & IM trap: trap exit grid 1 delta & $-5 V$ & $-5 V$ \\
\hline & IM trap: trap exit grid 2 low & $-63 V$ & $-63 V$ \\
\hline & IM trap: trap exit grid 2 delta & $-9 V$ & $-9 V$ \\
\hline & Acquisition: trap fill time & $1000 \mu \mathrm{s}$ & $1000 \mu \mathrm{s}$ \\
\hline & Acquisition: trap release time & $200 \mu \mathrm{s}$ & $200 \mu \mathrm{s}$ \\
\hline & IM drift tube: drift tube exit & $-210 \mathrm{~V}$ & $-210 V$ \\
\hline
\end{tabular}


Table S1(b). List of the tuning parameters applied in the post-IMS region.

\begin{tabular}{|c|c|c|c|}
\hline \multicolumn{2}{|c|}{ Experimental conditions } & \multirow{2}{*}{$\begin{array}{l}\text { Soft or harsh PRE-IMS } \\
\text { Soft POST-IMS } \\
-200 \mathrm{~V}\end{array}$} & \multirow{2}{*}{$\begin{array}{c}\text { Soft or Harsh PRE-IMS } \\
\text { Harsh POST-IMS } \\
-200 \mathrm{~V}\end{array}$} \\
\hline \multirow{18}{*}{ 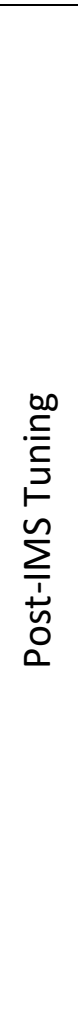 } & $\begin{array}{l}\text { IM rear funnel: rear funnel } \\
\text { entrance }\end{array}$ & & \\
\hline & IM rear funnel: rear funnel RF & $180 V_{p-p}$ & $180 V_{p-p}$ \\
\hline & IM rear funnel: rear funnel exit & $-26 \mathrm{~V}$ & $-35 \vee$ \\
\hline & IM rear funnel: IM Hex Entrance & $-24 \mathrm{~V}$ & $-32 \mathrm{~V}$ \\
\hline & IM rear funnel: IM Hex Delta & $-2 \mathrm{~V}$ & $-3 V$ \\
\hline & Optics 1: Oct Entrance Lens & $-21 \mathrm{~V}$ & $-27 V$ \\
\hline & Optics 1: Oct 1 DC & $-20 \mathrm{~V}$ & $-25 \mathrm{~V}$ \\
\hline & Optics 1: Lens 1 & $-19 V$ & $-20 \mathrm{~V}$ \\
\hline & Optics 1: Lens 2 & disabled & disabled \\
\hline & Quad: Quad DC & $-18 \mathrm{~V}$ & $-21 \mathrm{~V}$ \\
\hline & Quad: PostFilter DC & $-17 \mathrm{~V}$ & $-21 \mathrm{~V}$ \\
\hline & Cell: Gas flow & 20 psi & 20 psi \\
\hline & Cell: Cell Entrance & $-16 \mathrm{~V}$ & $-20 \mathrm{~V}$ \\
\hline & Cell: Hex DC & $-16 \mathrm{~V}$ & $-20 \mathrm{~V}$ \\
\hline & Cell: Hex Delta & $3 \mathrm{~V}$ & $3 \mathrm{~V}$ \\
\hline & Cell: Hex2 DC & $-12 \mathrm{~V}$ & $-14.6 \mathrm{~V}$ \\
\hline & Optics 2: Hex3 DC & $-11 V$ & $-12.9 \mathrm{~V}$ \\
\hline & Extractor: Ion focus & $-10 V$ & \\
\hline
\end{tabular}

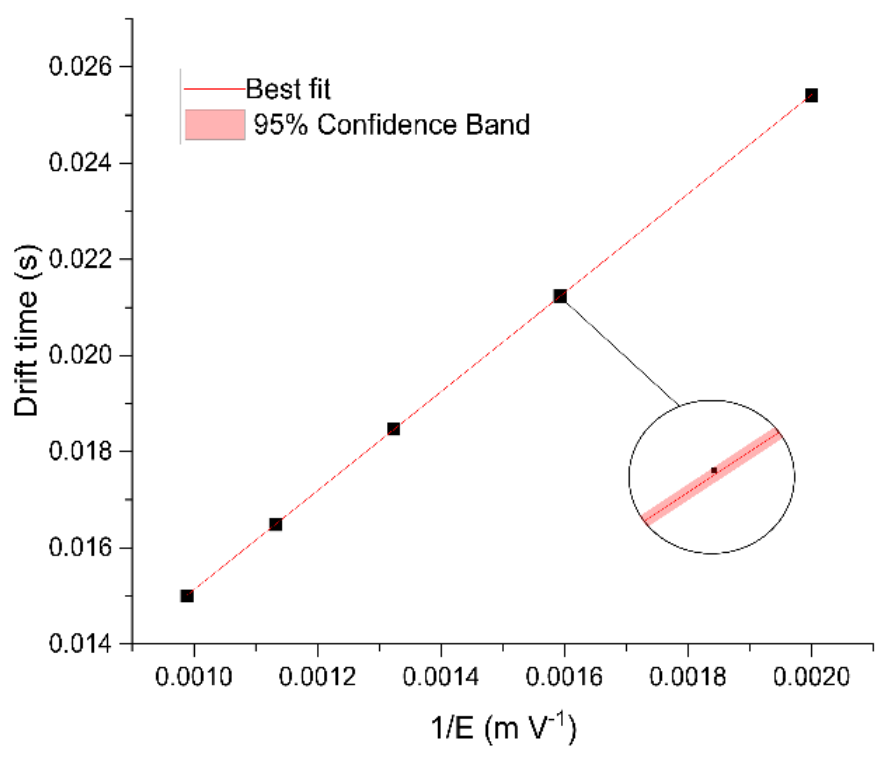

Figure S1. Linear regression of $\mathrm{P \# 8^{- }}$ phosphoric acid cluster anion $\left(\left[\left(\mathrm{H}_{3} \mathrm{PO}_{4}\right)_{8}-\mathrm{H}\right]^{-}\right)$. The slope was $10.287 \mathrm{~s} \mathrm{~V} \mathrm{~m}^{-1}$ and intercept $0.005 \mathrm{~m} \mathrm{~V}^{-1}$ with standard errors of $0.019 \mathrm{~s} \mathrm{~V} \mathrm{~m}^{-1}$ and 3 $10^{-5} \mathrm{~m} \mathrm{~V}^{-1}$ respectively . $\mathrm{R}^{2}$ was higher than 0.9999 . The zoomed region shows the $95 \%$ confidence bands. 
Table S2. List of supplementary experimental parameters used to perform ion mobility mass spectrometry measurement on the Synapt G2.

\begin{tabular}{|c|c|c|c|c|c|}
\hline \multicolumn{2}{|c|}{ ESI- V Resolution mode } & \multicolumn{2}{|c|}{ DC potentials $(\mathrm{V})$} & \multicolumn{2}{|c|}{ Traveling wave parameters } \\
\hline$m / z$ range & $50-4000$ & Trap Collision Energy & 5 & Source Wave Velocity (m/s) & 300 \\
\hline Capillary (kV) & 2.7 & Transfer Collision Energy & 0 & Source Wave Height (V) & 0.2 \\
\hline Source Temperature $\left({ }^{\circ} \mathrm{C}\right)$ & 90 & Trap DC Entrance & 3 & Trap Wave Velocity (m/s) & 300 \\
\hline Sampling Cone (V) & 60 & Trap DC Bias & 40 & Trap Wave Height (V) & 0.5 \\
\hline Extraction Cone (V) & 2 & Trap DC & -1 & IMS Wave Velocity (m/s) & 350 \\
\hline Source Gas Flow (mL/min) & 20 & Trap DC Exit & 0 & IMS Wave Height (V) & 20 or 15 \\
\hline Desolvation Temperature $\left({ }^{\circ} \mathrm{C}\right)$ & 250 & IMS DC Entrance & 25 & Transfer Wave Velocity $(\mathrm{m} / \mathrm{s})$ & 350 \\
\hline Cone Gas Flow (L/hr) & 0 & Helium Cell DC & 35 & Transfer Wave Height (V) & 5 \\
\hline Desolvation Gas Flow (L/hr) & 500 & Helium Exit & -5 & & \\
\hline Trap Gas Flow (mL/min) & 0.4 & IMS Bias & 0 & & \\
\hline Helium Cell Gas Flow & 180 & IMS DC Exit & 0 & & \\
\hline IMS Gas Flow (mL/min) & 70 & Transfer DC Entrance & $\begin{array}{c}\text { defa } \\
\text { ult }\end{array}$ & & \\
\hline $\begin{array}{l}\text { Sample Infusion Flow Rate } \\
(\mu \mathrm{L} / \mathrm{hr})\end{array}$ & 300 & Transfer DC Exit & $\begin{array}{l}\text { defa } \\
\text { ult }\end{array}$ & & \\
\hline
\end{tabular}




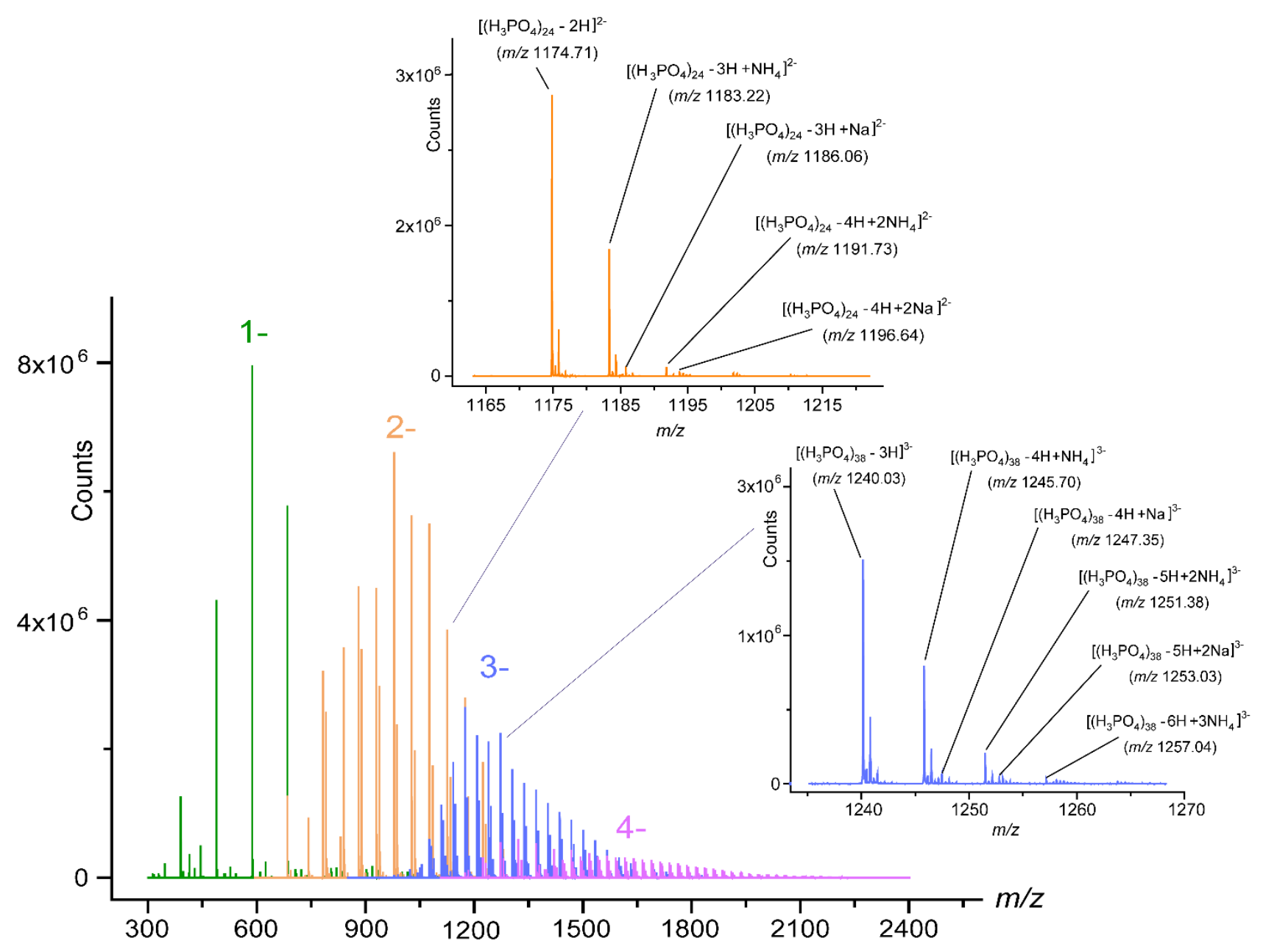

Figure S2. Phosphoric acid cluster anions mass spectrum extracted for charge state up to 4obtained in soft pre-IMS and soft post-IMS condition using an electric field of $5.0 \mathrm{~V} \mathrm{~cm}^{-1}$ in helium. The insets show doubly charged (orange) and triply charged (blue) ammonia and sodium adducts. 


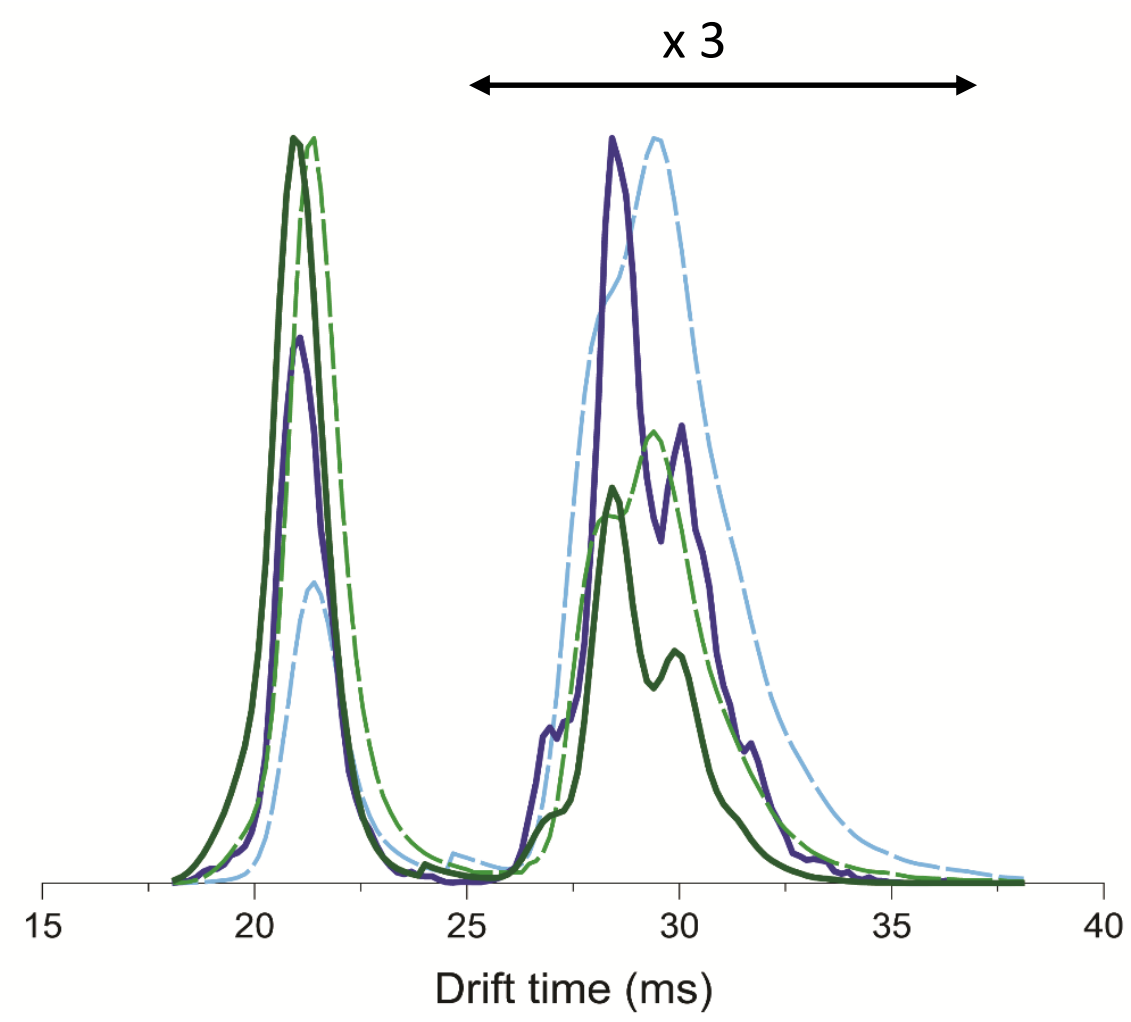

Figure S3. Extracted ion mobility spectra of $\mathrm{m} / \mathrm{z} 880.78$ ( $\mathrm{P \# 9^{- }}$ and $\mathrm{P} \# 18^{-}$and their precursor ions). Ion mobility with soft pre-IMS conditions: green traces; lon mobility with harsh pre-IMS conditions: purple and light blue traces. Harsh post IMS gradient: full lines (green and purple). Soft post IMS gradient: dashed lines (light green and light blue). The omitted y axes correspond to the signal intensity in arbitrary units normalized to the highest peak on display; the intensity corresponding to the signal of the singly charged cluster ions were multiplied by 3 , similarly to figure 3. 


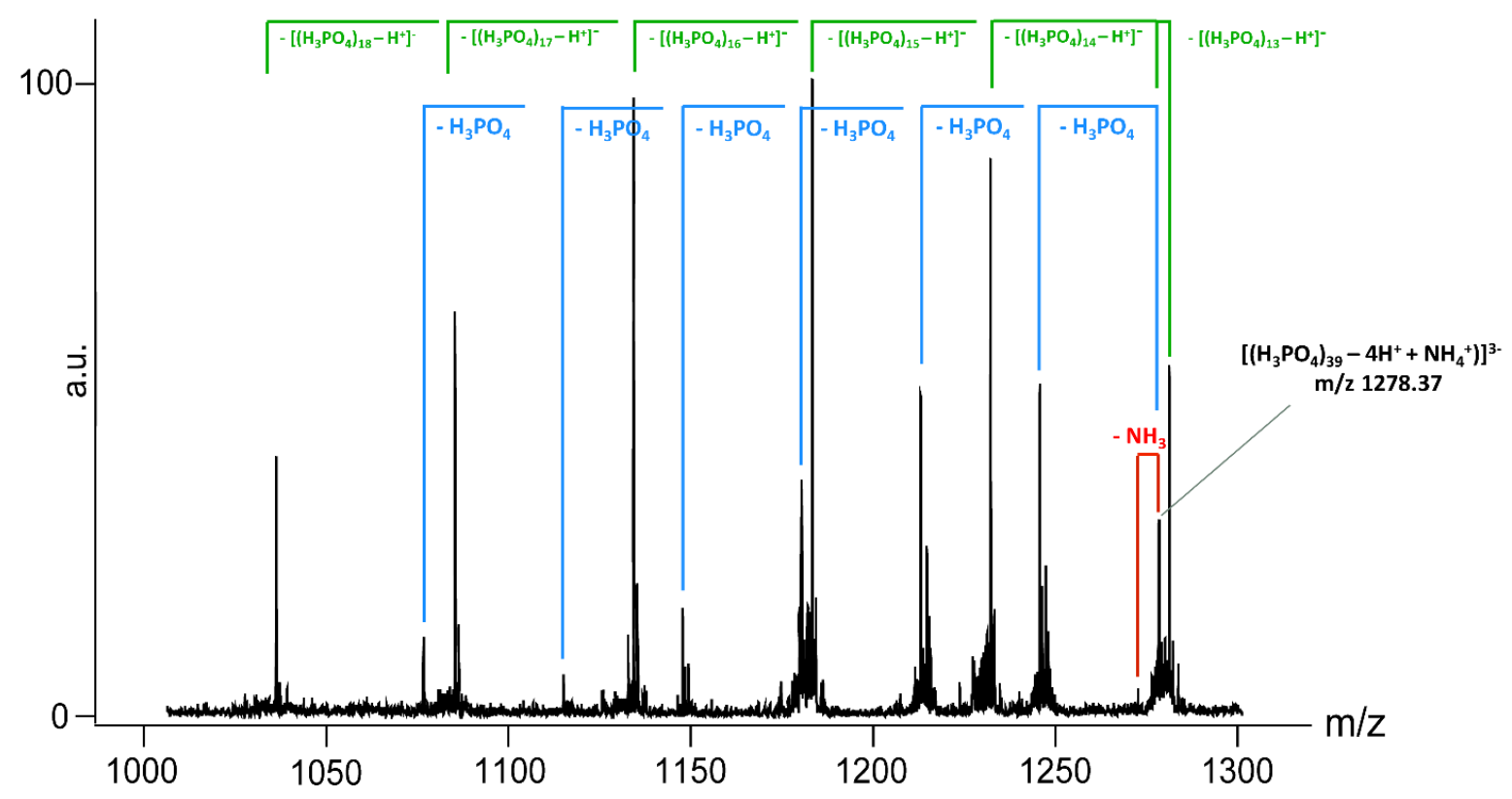

Figure S4. Extract of the fragment ion spectrum for the triply charged ammonia adduct $\left[\left(\mathrm{H}_{3} \mathrm{PO}_{4}\right)_{39}-4 \mathrm{H}+1 \mathrm{NH}_{4}\right]^{3-}$. Three different fragmentation pathways are present: the loss of neutral molecules of $\mathrm{H}_{3} \mathrm{PO}_{4}$ (in blue), the charge separation process with formation of doubly charged ammonia adducts (in green) and the neutral loss of $\mathrm{NH}_{3}$ leading to the production of the pure phosphoric acid cluster ion $\left[\left(\mathrm{H}_{3} \mathrm{PO}_{4}\right)_{39}-3 \mathrm{H}\right]^{3-}$ (in red). The $\mathrm{CID}$ experiment was performed in the trap cell of a Synapt G2 using a collision voltage of $5 \mathrm{eV}$.

Table S3: Experimental ${ }^{\mathrm{DT}} \mathrm{CCS}$ He values $\left(\AA^{2}\right)$ of figure 4 for tuning mix anions, in helium at 296.6 $\mathrm{K}$ compared to the Anal Chem 2017 [1] ${ }^{\mathrm{DT}} \mathrm{CCS}_{\mathrm{He}}$ at $296 \mathrm{~K}$.

\begin{tabular}{|c|c|c|c|c|c|c|c|c|c|c|}
\hline & \multicolumn{4}{|c|}{$\begin{array}{l}\text { MIXTURE WITH } \mathrm{H}_{3} \mathrm{PO}_{4} \\
\text { (JANUARY 2019) }\end{array}$} & \multicolumn{2}{|c|}{$\begin{array}{l}\text { TUNEMIX anions } \\
\text { (MAY 2018) }\end{array}$} & \multicolumn{2}{|c|}{ All experiments } & \multicolumn{2}{|c|}{ Anal Chem 2017 [1] } \\
\hline$m / z$ & \multicolumn{2}{|c|}{$\begin{array}{l}\text { Soft-pre-IMS } \\
\text { (F 350V) }\end{array}$} & \multicolumn{2}{|c|}{$\begin{array}{l}\text { Harsh pre-IMS } \\
(600 \mathrm{~V})\end{array}$} & \multicolumn{2}{|c|}{ Harsh pre IMS (600 V) } & $\begin{array}{c}\text { Mean } \\
{ }^{\mathrm{DT} C C S_{\mathrm{He}}} \\
\left(\AA^{2}\right)\end{array}$ & $\begin{array}{c}\sigma_{\mathrm{CCS}} \\
\left(\left(\AA^{2}\right)\right) \\
n=6\end{array}$ & $\begin{array}{c}{ }^{\mathrm{DT}} \mathrm{CCS}_{\mathrm{He}} \\
\left(\AA^{2}\right)\end{array}$ & $\begin{array}{c}\sigma_{\operatorname{CCS}(}\left(\AA^{2}\right) \\
n=3\end{array}$ \\
\hline 602 & 118.7 & 119.0 & 119.0 & 118.8 & 118.2 & 119.0 & 118.8 & 0.3 & 118.6 & 1.5 \\
\hline 1034 & 191.2 & 191.5 & 191.3 & 191.0 & 189.1 & 190.1 & 190.7 & 0.9 & 190.0 & 1.3 \\
\hline 1334 & 215.9 & 216.6 & 216.7 & 216.6 & 214.9 & 216.6 & 216.2 & 0.7 & 215.5 & 1.4 \\
\hline 1634 & 245.4 & 245.8 & 245.9 & 245.8 & 242.7 & 245.4 & 245.2 & 1.2 & 244.3 & 1.5 \\
\hline 1934 & 273.7 & 273.1 & 272.9 & 273.1 & 271.6 & 273.4 & 273.0 & 0.7 & 272.2 & 1.7 \\
\hline 2234 & 296.1 & 296.8 & 297.0 & 297.1 & 295.5 & 298.2 & 296.8 & 0.9 & 295.8 & 1.9 \\
\hline
\end{tabular}


Table S4. Experimental ${ }^{D T} \mathrm{CCS}_{\mathrm{He}}$ values $\left(\AA^{2}\right)$ at $296.6 \mathrm{~K}$ of figure 5 for sample $\mathrm{H}_{3} \mathrm{PO}_{4}$ cluster anions with charge state between 1 - and 4 - in different experimental conditions The last columns represent the mean CCS ( ${ }^{\mathrm{DT}} \mathrm{CCS}_{\mathrm{He}}$ ) and the standard deviation of CCS ( $\left.\sigma_{\mathrm{CCS}}\right)$ values.

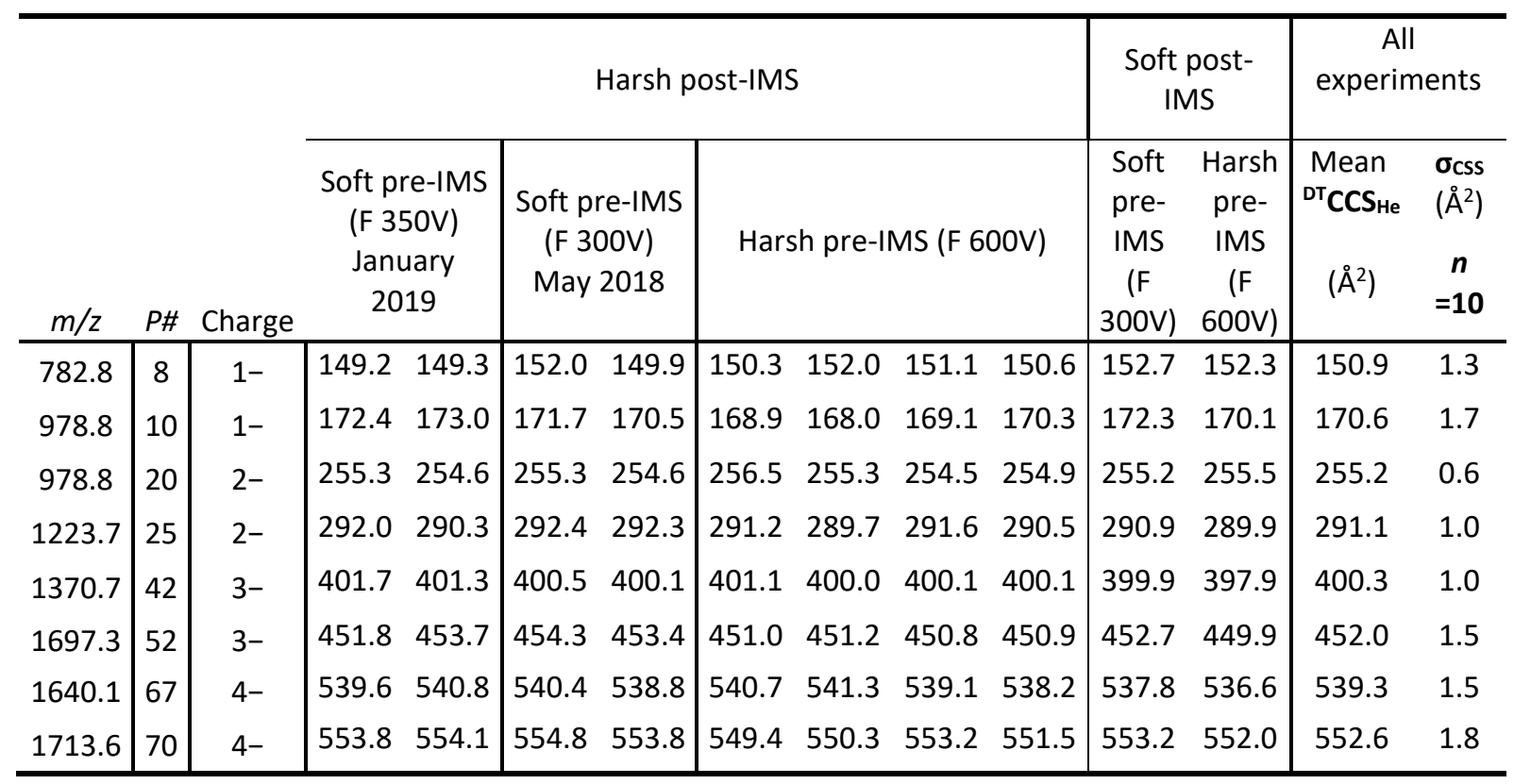

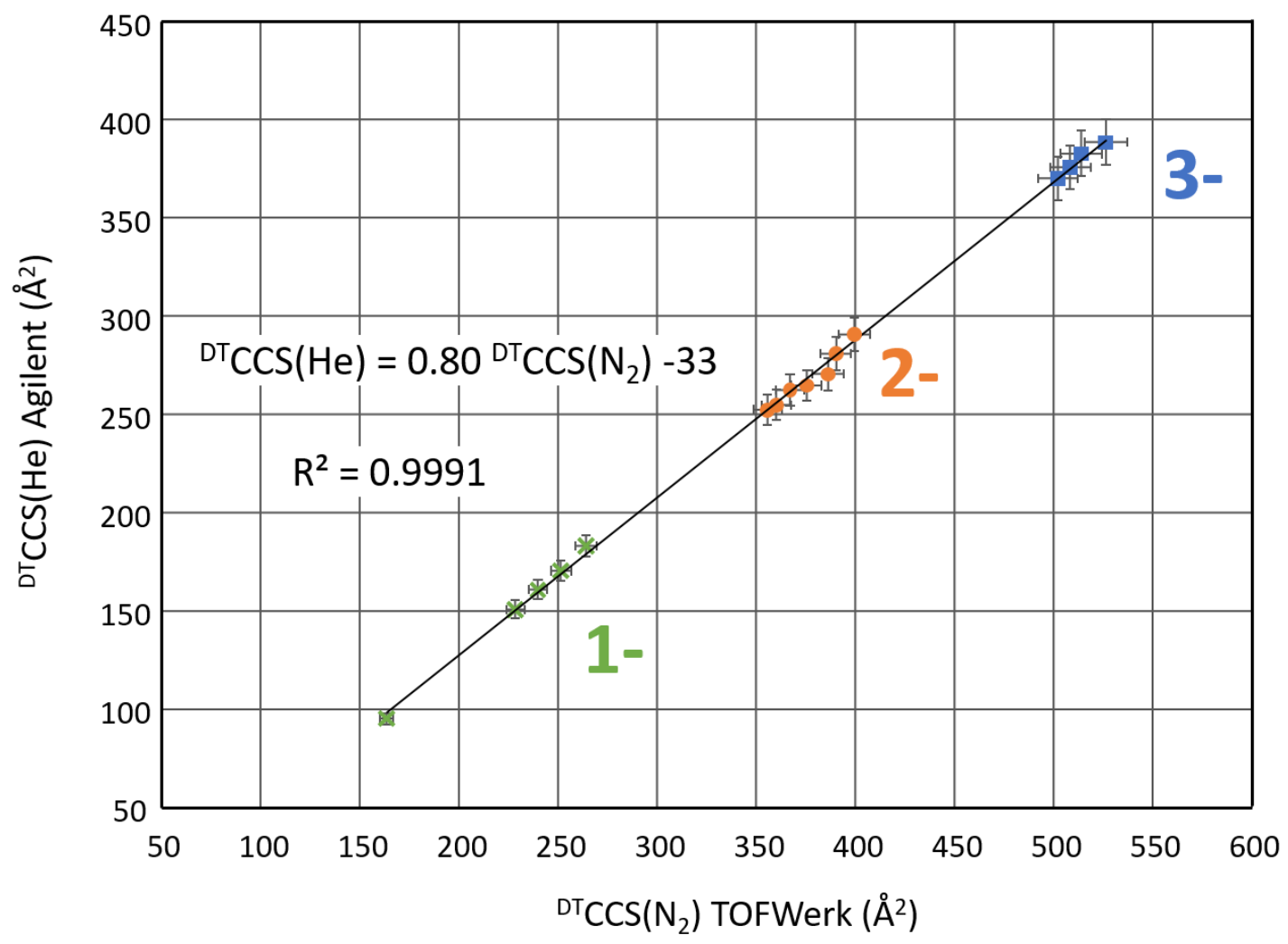

Figure S5. Correlation between the ${ }^{\mathrm{DT}} \mathrm{CCS}(\mathrm{He})$ values in this study with ${ }^{\mathrm{DT}} \mathrm{CCS}\left(\mathrm{N}_{2}\right)$ values determined in our previous work [ref 19]. Green crosses are singly charged phosphoric cluster anions, orange circles are doubly charged charged phosphoric cluster anions, and blue squares are triply charged charged phosphoric cluster anions. 